

\section{DISCLAIMER}

This report was prepared as an account of work sponsored by an agency of the United States Government. Neither the United States Government nor any agency Thereof, nor any of their employees, makes any warranty, express or implied, or assumes any legal liability or responsibility for the accuracy, completeness, or usefulness of any information, apparatus, product, or process disclosed, or represents that its use would not infringe privately owned rights. Reference herein to any specific commercial product, process, or service by trade name, trademark, manufacturer, or otherwise does not necessarily constitute or imply its endorsement, recommendation, or favoring by the United States Government or any agency thereof. The views and opinions of authors expressed herein do not necessarily state or reflect those of the United States Government or any agency thereof. 


\section{DISCLAIMER}

Portions of this document may be illegible in electronic image products. Images are produced from the best available original document. 


\section{DISCLAIMER}

This document was prepared as an account of work sponsored by an agency of the United States Government. Neither the United States Government nor the University of California nor any of their employees, makes any warranty, express or implied, or assumes any legal liability or responsibility for the accuracy, completeness, or usefulness of any information, apparatus, product, or process disclosed, or represents that its use would not infringe privately owned rights. Reference herein to any specific commercial products, process, or service by trade name, trademark, manufacturer, or otherwise, does not necessarily constitute or imply its endorsement, recommendation, or favoring by the United States Government or the University of California. The views and opinions of authors expressed herein do not necessarily state or reflect those of the United States Government thereof, and shall not be used for advertising or product endorsement purposes.

Work performed under the auspices of the U.S. Department of Energy by Lawrence Livermore National Laboratory under Contract W-7405-Eng-48. 
UCRL-52756

Distribution Category UC-11

\title{
Evaluation of reservoir properties in a portion of the Salton Sea Geothermal Field
}

\author{
John G. Morse \\ Randolph Stone
}

Manuscript date: April 4, 1979

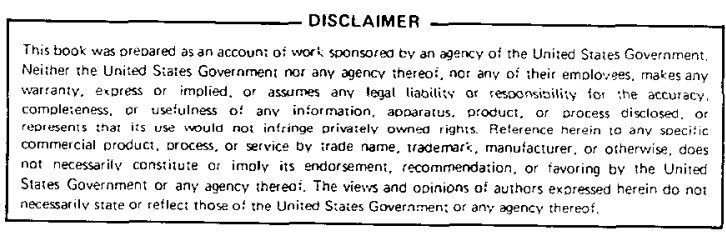

LAWRENCE LIVERMORE LABORATORY

University of California $\bullet$ Livermore, California 94550 

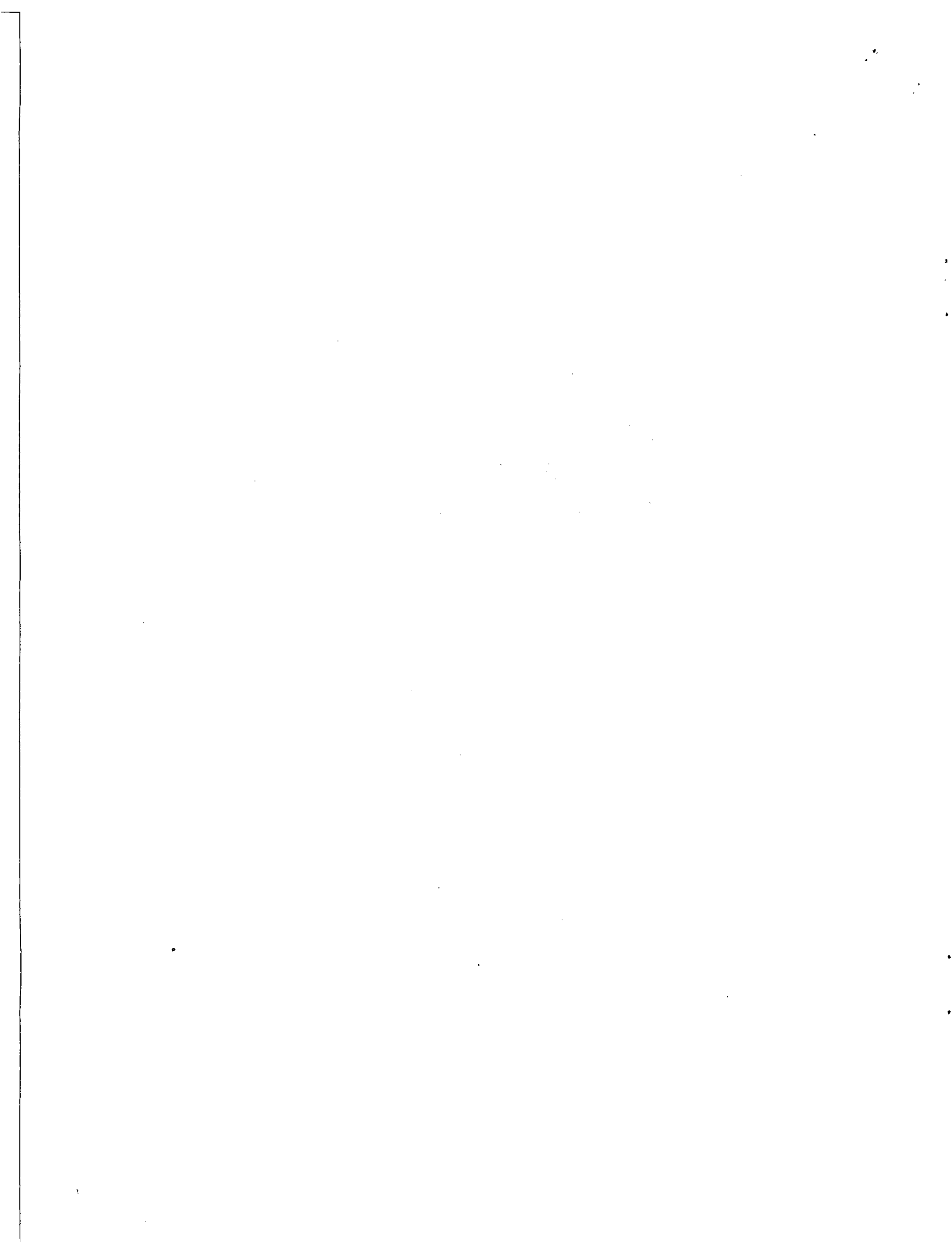

.

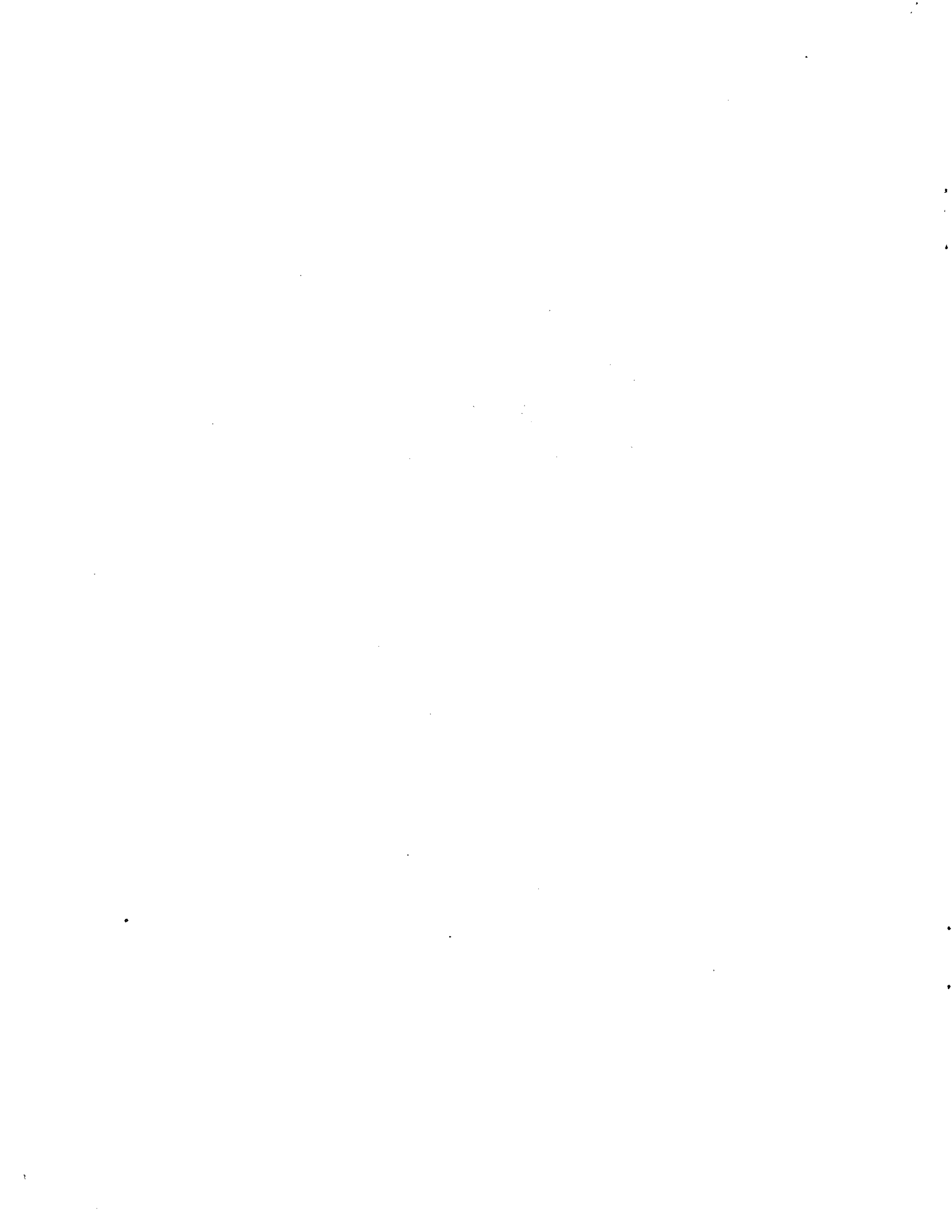


CONTENTS

Nomenclature • • • • • • • • • • • • • • • • • • •

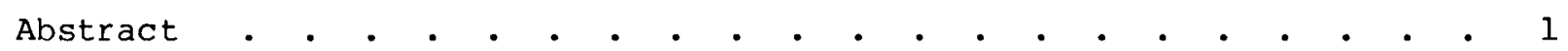

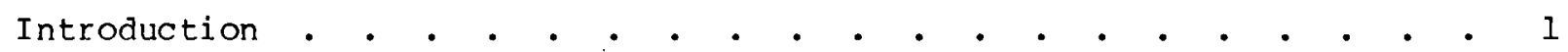

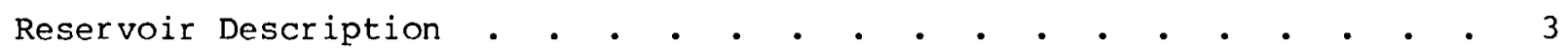

Geology • • • • • • • • • • • • • • • • • • • • 3

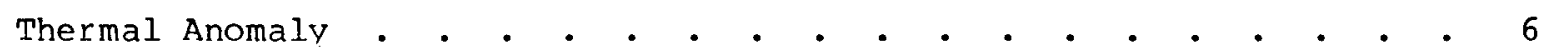

Hydraulics and Hydrology • • • • • • • • • • • • • • • 7

Geothermal Well Characteristics • • • • • • • • • • • • 99

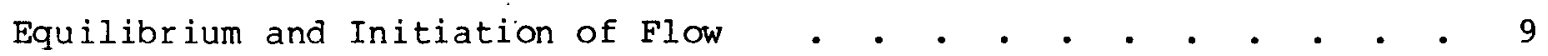

Surging flow • • • • • • • • • • • • • • • • • • • 10

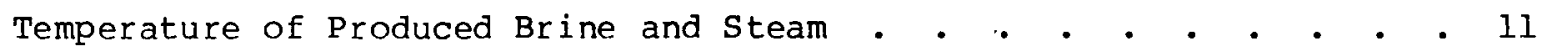

Return to Equilibrium After Flow . • • • • • • • . • . . 12

Instrumentation for Reservoir Pressure Measurement . • • . • . . 12

Direct Pressure Measurement • . • • . • • • . • . . . . 14

Hewlett-Packard Quartz Pressure Gauge . . . . . . . . . 14

Paroscientific Quartz Pressure Gauges . • • • • . • . . 16

Kuster Pressure Gauge • • • • • • • • • • • • • . 17

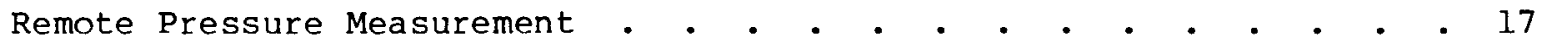

Sperry Sun Pressure-Transmission System • • • . • • • . 18

An Improved Pressure-Transmission System . • • • . • • . 19

Geothermal Well Tests • • • • • • • • • • • • • • • • 21

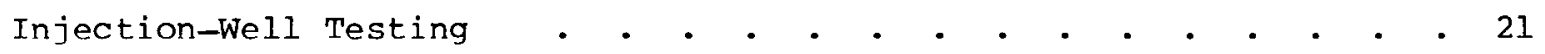

Production-Well Testing • • • • • • • • • • • • • • 30

Results from Observation Wells . . • • • • • . • . • . • 36

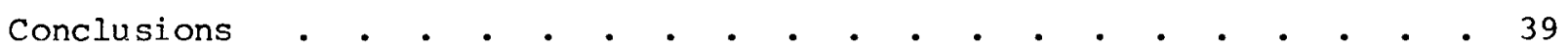

Acknowledgements • • • • • • • • • • • • • • • • • . • 40

Appendix A--Well Field Operational History • • • • • • • • • • . 43

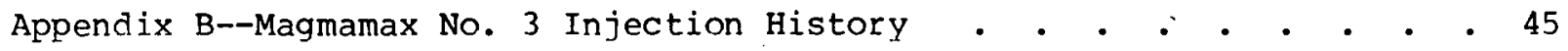

References . • • • • • • • • • • • • • • • • • • • 51 


\section{Parameters}

$\mathrm{k}$ = permeability

$\mathrm{h}=$ formation thickness

$\mu=$ fluid viscosity

$q=$ flow rate

$m=$ slope of linear portion of plot of pressure vs logarithm of time

$C=$ constant for dimensional conversion

$d=$ formation porosity

$c_{t}=$ system total compressibility
Field units

millidarcy, md

feet, ft

centipoise, $c p$

gallons per minute, gpm

psi/log cycle of time

5573.8

dimensionless fraction

$\mathrm{psi}^{-1}$

Relation between permeahility and other parameters, used in analysis of single-well drawdown, buildup, and falloff tests:

$$
\mathrm{k}=\frac{\mathrm{qC} \mu}{\mathrm{hm}}
$$


IN A PORTION OF THE

SALTON SEA GEOTHERMAL FIELD

\begin{abstract}
A series of pressure-transient tests was performed using several geothermal wells in the southwestern portion of the Salton Sea Geothermal Field in the Imperial Valley, California. The objective of the tests was to evaluate the permeability and storage capacity of the geothermal reservoir. Measurement of pressure transients in the corrosive, high-temperature environment of geothermal wells was made possible by modifying commercially available instrumentation and fabrication of pressure-sensing devices from very corrosion-resistant material:

Analysis of pressure-transient data associated with production from and injection into the geothermal reservoir provides estimates of reservoir permeability that vary from 70 to $1000 \mathrm{md}$, with most of the values in the range from 70 to $22.0 \mathrm{md}$. A reservoir porosity-compressibility product of 2.8 $\times 10^{-6} \mathrm{psi}^{-1}$ was derived. The pressure responses to the tests appear to he characteristic of a confined, nonleaky reservoir. The vertical permeability of a 40-ft-thick shale layer within the reservoir was estimated to be between 0.1 and $1 \mathrm{md}$. No lateral positive or negative hydraulic boundaries were detected. The pressure response of the primary spent-brine injection well was indicative of combined fracture and matrix flow in the reservoir. This well's lifetime with no brine treatment prior to injection would be about 150 days at an injection flow rate of $600 \mathrm{gpm}$; simply cycling the brine through settling tanks prior to injection would increase the well's useful life to about two years at the same injection rate.
\end{abstract}

\title{
INTRODUCTION
}

A series of pressure-transient tests was conducted on deep wells tapping the geothermal reservoir in the vicinity of the Geothermal Loop Experimental Facility (GLEF) located in the Salton Sea Geothermal Field (SSGF) of 
California's Imperial Valley (Fig. 1). The objective of the tests was to measure the permeability and storage capacity of the reservoir and to investigate the hydraulic communication between wells. Evaluation of these reservoir properties was necessary to provide input to models of reservoir behavior during production of geothermal energy. The tests were an integral part of a reservoir-evaluation effort undertaken as part of the Lawrence Livermore Laboratory Geothermal Industrial Support Program, conducted with the consent and cooperation of the Magma Power Company and San Diego Gas and Electric Company (SDG\&E) .

Deeply buried sedimentary rock units containing hot brine in fracture and interstitial spaces constitute the geothermal reservoir and store the accumulate thermal energv in the SSGF. The GLEF has been used for testing methods of extracting energy from the geothermal fluids produced from the nearby geothermal wells. Most of the geothermal fluids produced from the reservoir at the SSFG are cooled at the surface in passing through the GLEF. The cooled, spent, geothermal brine is then injected into wells completed at greater depth

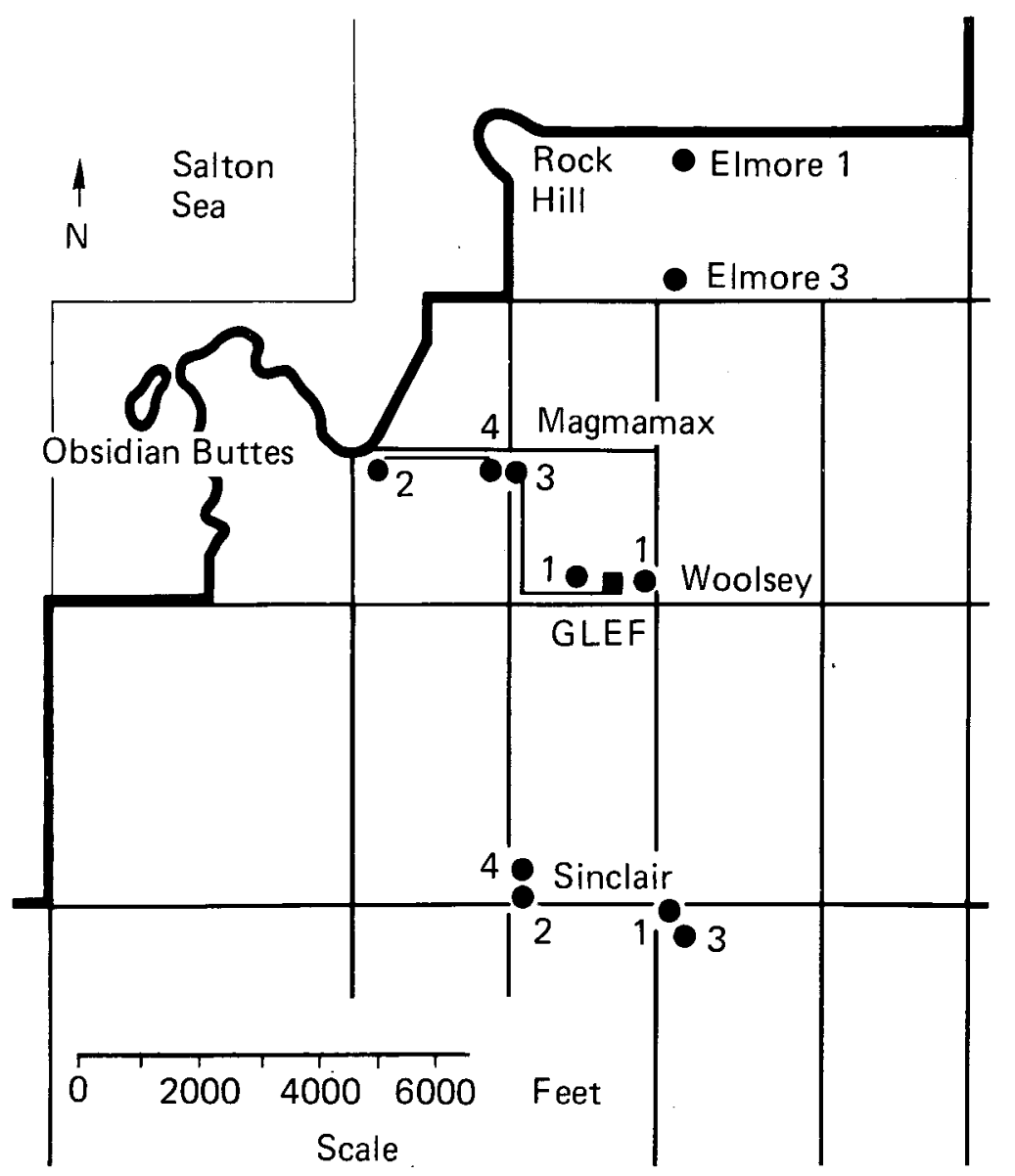

FIG. 1. The area around the Geothermal Loop Exper imental Facility (GLEF) in the Salton Sea Geothermal Field, showing the location of the wells studied. 
than the production wells. Subsurface injection of the spent brine is the only environmentally acceptable means of disposing of it, and may provide some benefit by helping to maintain reservoir pressure.

The history of production and injection of geothermal fluids in the GLEF well field was compiled to provide a backdrop for the analysis of the transient pressure data obtained during the well tests. All of the well tests were hampered by uncertainty in production and injection flow rate and pressure data, temperature and corrosion problems, reservoir heterogeneity, and complex geometries in the production and injection zones of the wells that were tested. Flow rates were not only uncertain, but varied from 200 to $1000 \mathrm{gpm}$ over a given operating cycle. Because well tests had to be coordinated with the GLEF operating schedule, the testing conditions were even less optimal The uncertainty of start-up and shutdown times caused us to miss testing opportunities. Stable reservoir-pressure conditions were seldom reached before production and injection.

\section{RESERVOIR DESCRIPTION}

GEOLOGY

The Salton Sea Geothermal Field is located at the southeastern end of the Salton Sea (Fig. 2). The field is in the physiographic section known as the Salton Trough, a sediment-filled structural depression ${ }^{l}$ that is part of a structural transition from the oceanic crustal spreading center associated with the East Pacific Rise to a major continental fault system that includes the San Andreas Fault. ${ }^{2}$ The Colorado River delta radiates across the Salton Trough from the point where the river flows into it. The sequence of sedimentary rocks in the Salton Trough is approximately 20,000 ft thick and composed primarily of detritus from the Colorado River. ${ }^{3}$ Unaltered deltaic sediments in the Salton Trough are predominantly composed of quartz and calcite, with subordinate amounts of dolomite, feldspar, clay minerals, and mica. ${ }^{4}$

A detailed study of cuttings, samples, and cores from wells in the vicinity of the GLEF ${ }^{3}$ showed that the sedimentary sequence in the southwestern portion of the SSGF, from the surface down to $4000 \mathrm{ft}$, is divided into three units: cap rock, unaltered reservoir rock, and hydrothermally-altered reservoir rock. The cap rock, a thick layer of low permeability that extends 

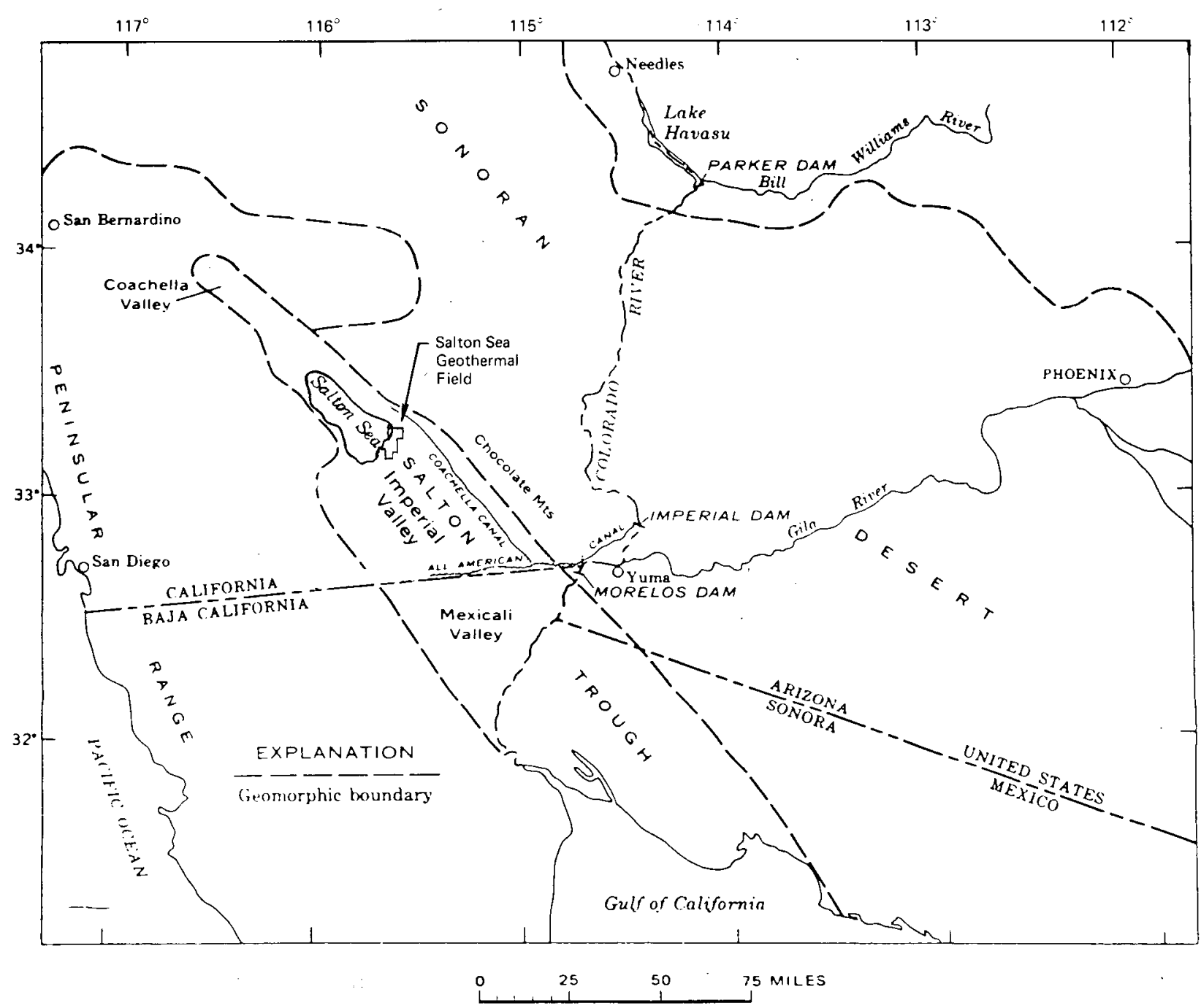

FIG. 2. The Salton Trough and surrounding region.

to approximately $1100 \mathrm{ft}$ below the surface, functions as an upper barrier to deep convection currents. It also acts as a thermal insulator to hold heat in the deeper geothermal reservoir. The upper $600 \mathrm{ft}$ of the cap rock layer is composed of unconsolidated silt, sand, and gravel; from 600 to $1100 \mathrm{ft}$ there is a clay-silt-evaporite sequence that may have undergone a self-sealing process by interacting with the hot brine in the geothermal reservoir below. ${ }^{3}$ The reservoir rock from 1100 to $4000 \mathrm{ft}$ consists of layered sequences of shale and sandstone. The transition from unaltered to hydrothermally altered reservoir rocks is marked by the appearance of epidote as the product of hydrothermal alteration of calcite. ${ }^{3}$ The hydrothermal alteration and resulting secondary greenschist mineralization appear to reduce the primary permeability and porosity of the reservoir rock. Secondary porosity and 
permeability are dominant in the hydrothermally-altered zone and apparently result from on-going natural fracturing. The natural fracturing is related to the location of the SSGF in a region of active crustal faulting. The permeability of the fractures may be enhanced by injection pressures in the vicinity of injection wells.

In the vicinity of the GLEF, three stratigraphic marker horizons have been identified and correlated between points of subsurface control. ${ }^{5-7}$ These marker horizons are the bottom of the cap rock, an 80-ft-thick shale unit overlain by uniformly interbedded sandstones and shales, and an ash layer. The wells involved in this study are shown in Fig. 3, along with the cap rock, the unaltered and altered reservoir zones, and the marker horizons. The structural picture that emerged from the subsurface studies shows a broad syncline in the area of the SSGF with an east-west axis roughly perpendicular to the axis of the Salton Trough. ${ }^{6}$ The syncline has a shallow westward plunge toward the center of the Trough (Fig. 4).

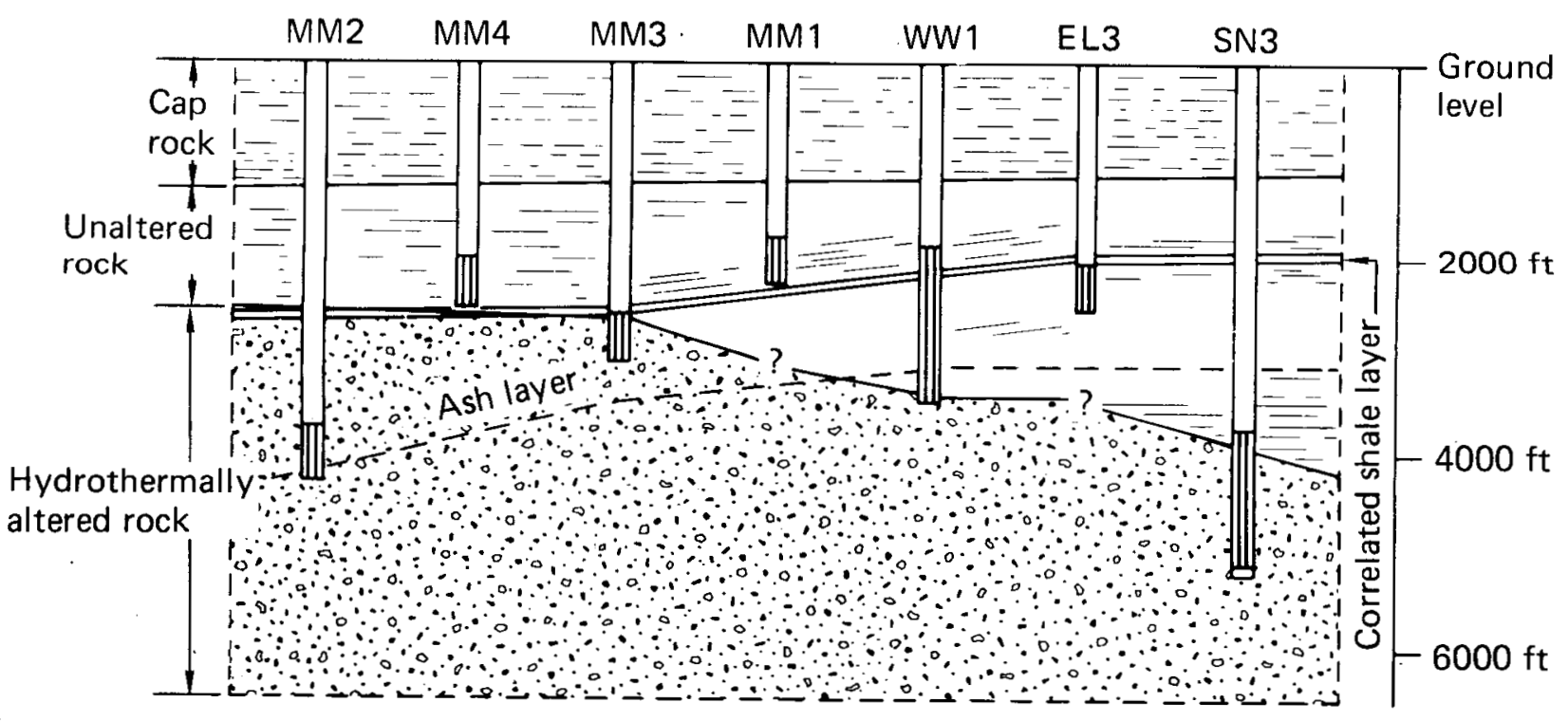

FIG. 3. Schematic cross section of the wells involved in the well testing program, showing completion details within the geothermal reservoir, the bottom of the cap rock, and the correlated shale and ash layers. The striped parts of the wells indicate perforated sections. (Horizontal distances between wells are not to scale--they are spaced evenly for diagramming conven ience.) 


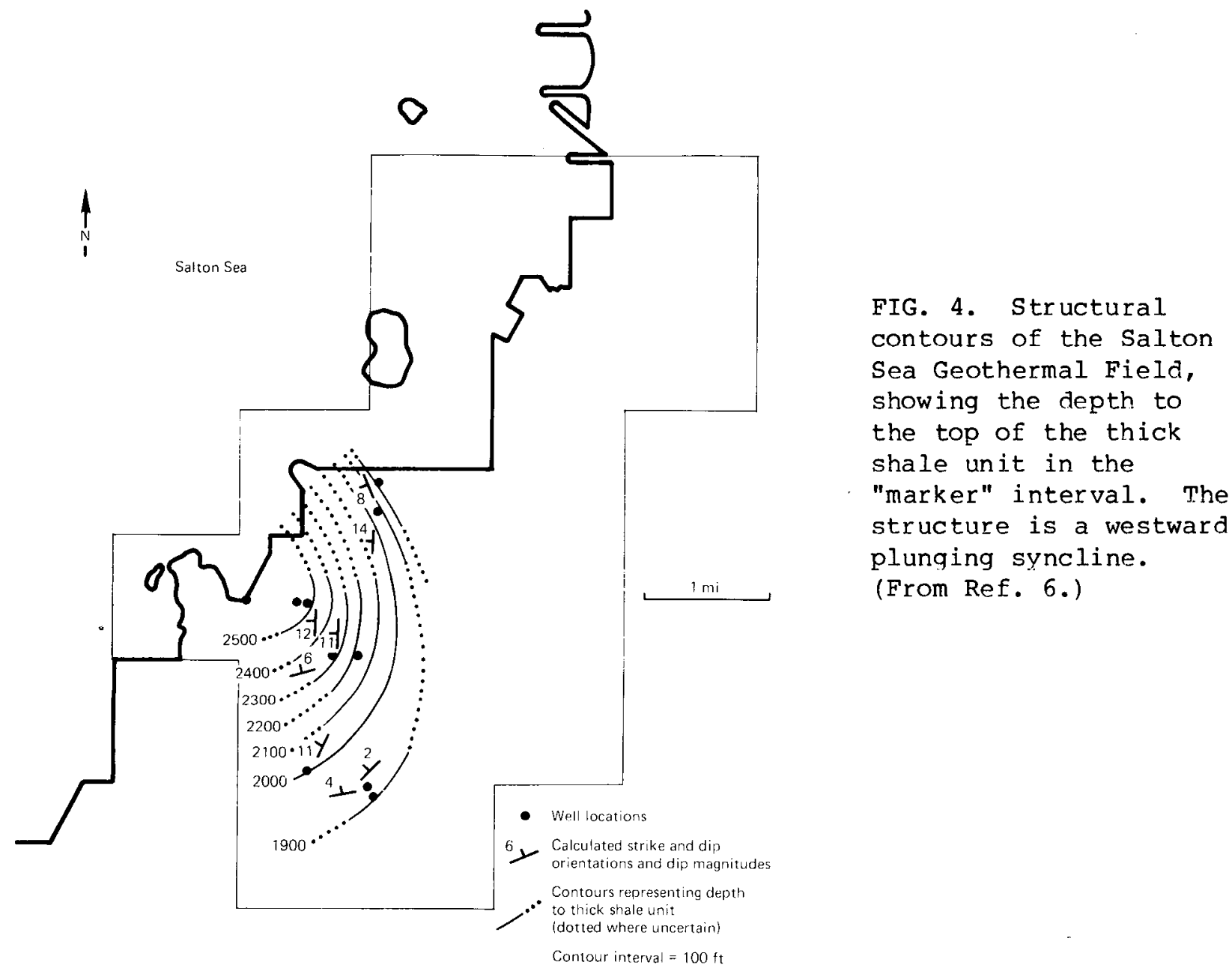

THERMAL ANOMALY

The SSGF is thought to overlie an active crustal spreading center where deep crustal convection transports heat toward the surface at rates greater than normal. There are possibly three or four of these small spreading centers, connected by faults, extending from near the southeastern end of the Salton Sea to its northeastern side. ${ }^{8}$ These inferred spreading centers coincide fairly well with magnetic anomalies in the area. A basaltic intrusion, below the geothermal reservoir, associated with the spreading center and magnetic anomaly at the SSGF has been postulated to account for the geothermal anomaly there.

Temperatures measured in deep wells of the SSGF provide the basis for a description of the thermal anomaly. Reservoir temperatures at 1000, 2000, and $3000 \mathrm{ft}$ below the surface are contoured to provide this areal description, as shown in Figs. 5, 6, and 7 , respectively. 


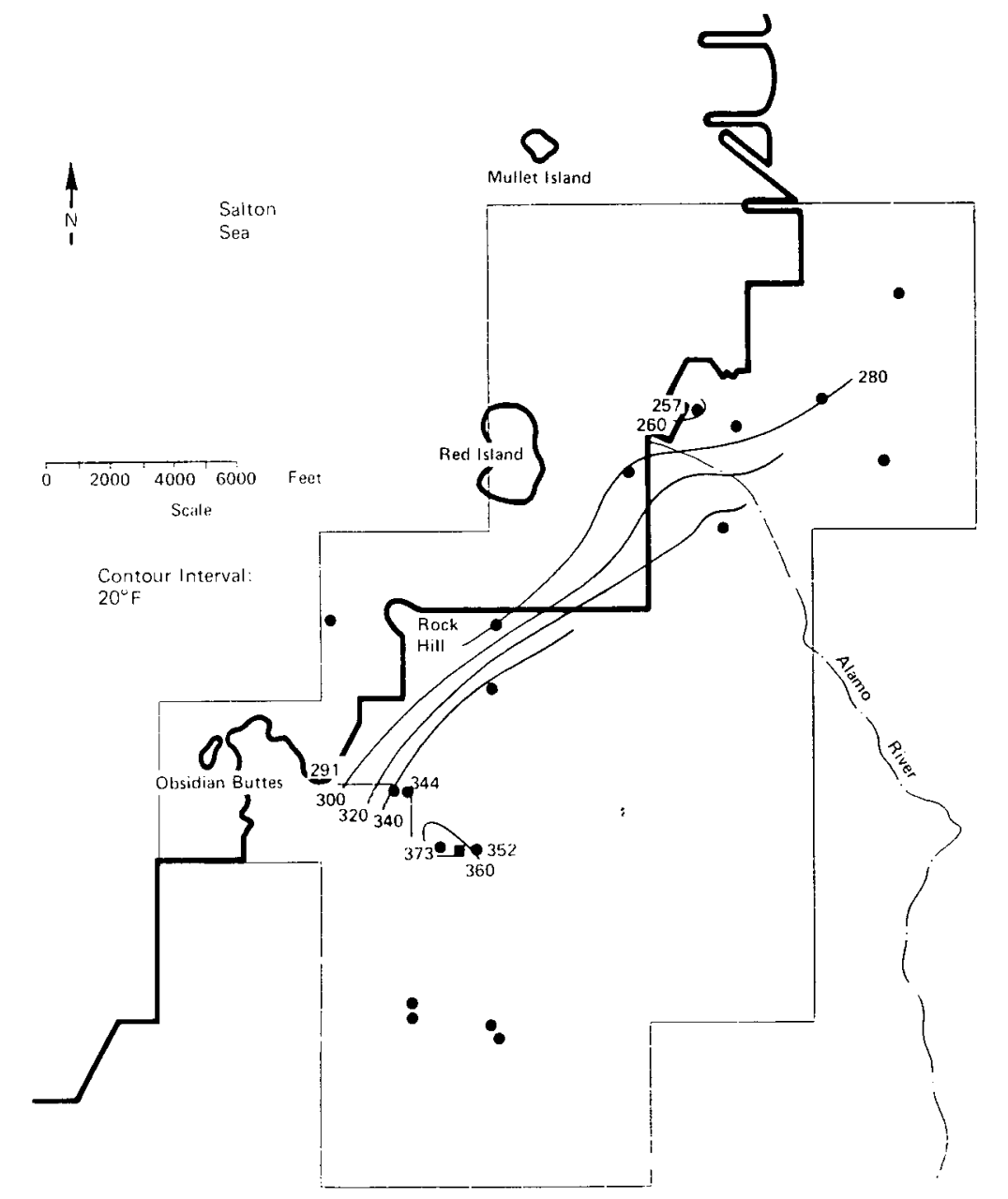

FIG. 5. Temperature contours in the Salton Sea Geothermal Field at 1000 ft below ground level. (From Ref. 5.)

HYDRAULICS AND HYDROLOGY

Fluid pressures within the geothermal reservoir are hydrostatic and change vertically at the constant rate of $0.433 \mathrm{psi} / \mathrm{ft}$. Both temperature and salinity increase with depth, and their opposing effects on brine density compensate each other.

The hydrologic relationship between near-surface ground water in the upper part of the cap rock and the brine in the geothermal reservoir has not been studied in detail. The cap rock, which helps keep heat in the reservoir, also restricts vertical mixing of near-surface ańd geothermal fluids. Some natural upflow of geothermal fluids to the surface, presumably through faults, is shown by the mud pots and feeble hot springs that occur in the SSGF. ${ }^{9}$ The lower Colorado River (the delta reach) may be the source of the geothermal brine. The stable hydrogen and oxygen isotopic compositions of the brine and 


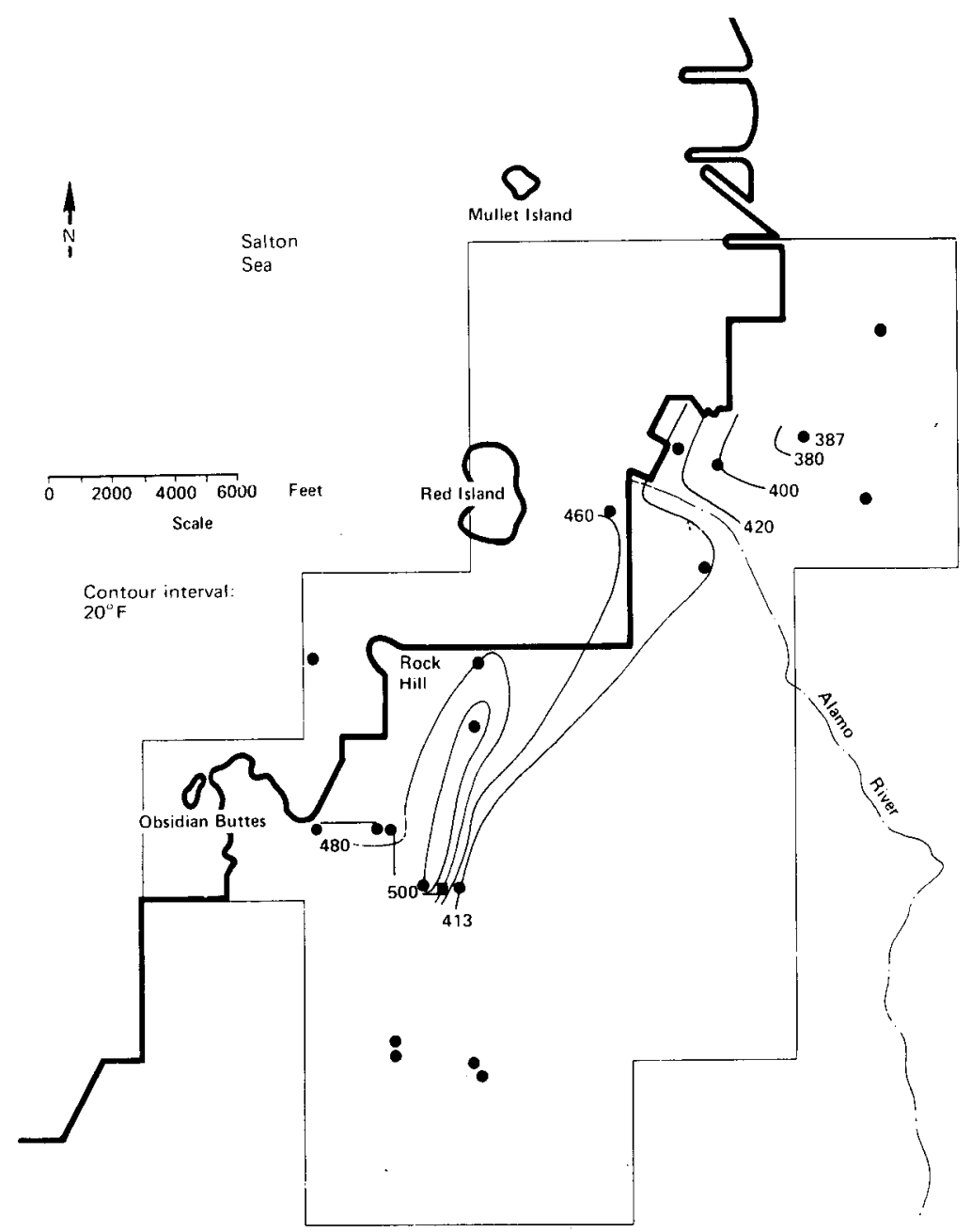

FIG. 6. Temperature contours in the Salton Sea Geothermal Field at $2000 \mathrm{ft}$ below ground level. (From Ref. 5.) 


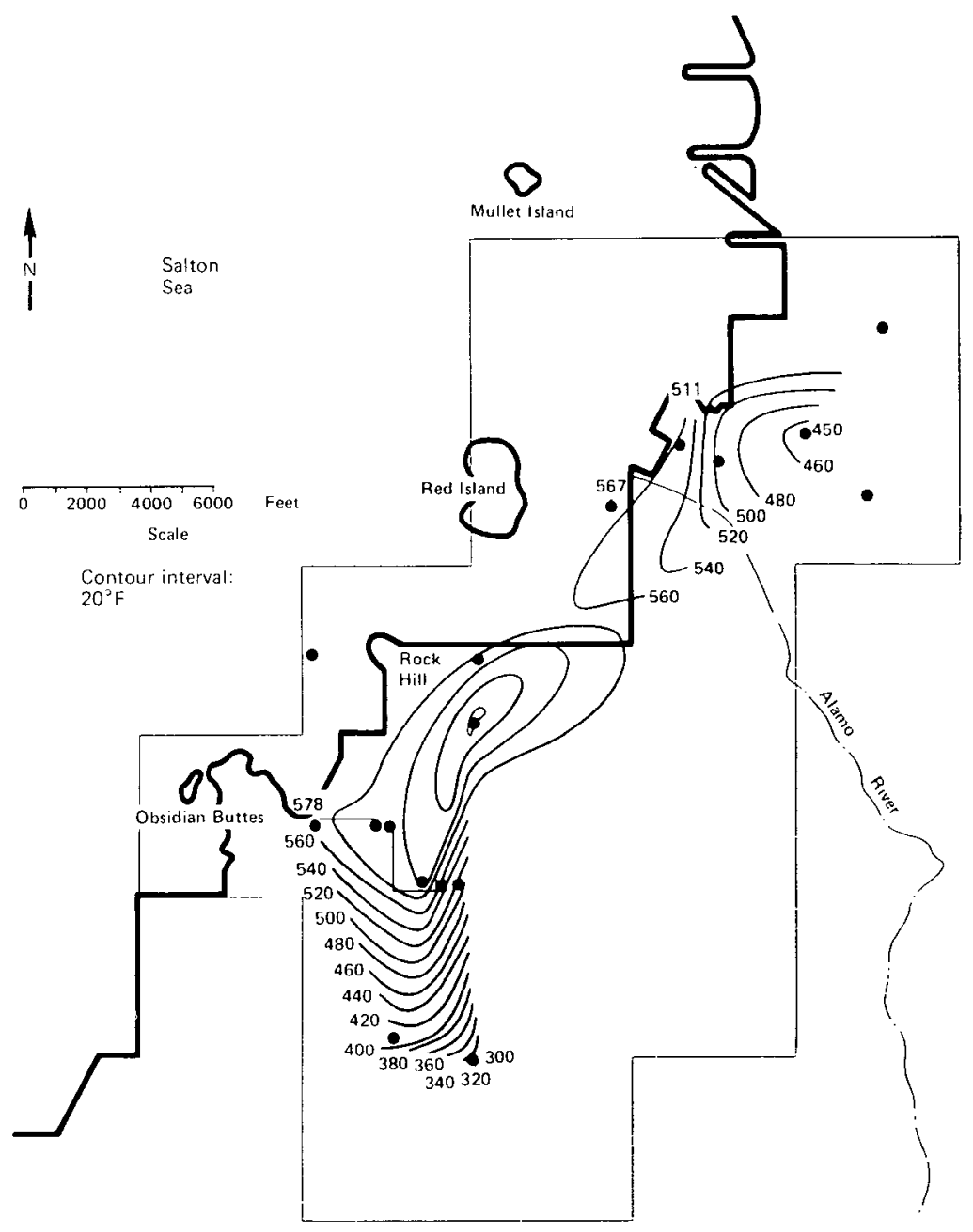

FIG. 7. Temperature contours in the salton Sea Geothermal Field at $3000 \mathrm{ft}$ below ground level. (From Ref. 5.)

water from the lower Colorado River are related. ${ }^{10}$ Natural brine flow within the geothermal reservoir, to the extent that any is occurring, is probably from southeast to northwest, toward the Salton Sea.

GEOTHERMAL WELL CHARACTERISTICS

\section{EQUILIBRIUM AND INITIATION OF FLOW}

Geothermal wells at equilibrium in the SSGF have hydrostatic pressure profiles. Static wellhead pressures, however, can vary from +60 psig to atmospheric. The variation in wellhead pressure is a function of the density of the liquid in the wellbore. A well filled with a column of brine at equilibrium with the static temperature profile of the well will have a 
free-surface liquid level of from 50 to $150 \mathrm{ft}$ below ground level and an atmospheric wellhead pressure. A well filled with a column of relatively fresh water at equilibrium with the static temperature profile will have liquid to the surface and a positive wellhead pressure (greater than atmospheric).

Priming is necessary to initiate the flow of hot brine and steam from the geothermal production wells. Once primed, the wells continue to flow. Priming is accomplished either by bubbling nitrogen into the wells or by displacing the brine in the wellbore with lighter low-salinity water. Both techniques reduce the wellbore pressure, allowing some brine to flash to steam, and produce sufficient hot brine to sustain well flow. The least expensive and most common technique is the fresh-water prime. As the column of fresh water in the wellbore heats up, it builds a wellhead pressure of 150 to 200 psi. When the well is opened, the fresh water flows out, bringing hot brine from the production zone behind it. If the brine reaches the upper portion of the well without much cooling, some of it flashes to steam, producing sufficient wellbore pressure reduction to sustain flow. The wells thus produce a mixture of brine and steam.

The fresh-water prime has several disadvantages. Introducing oxygenated water can increase well-casing corrosion problems and possible incompatibility of the prime water with the reservoir brine can cause skin damage (reduction in permeahility of the reservoir) in the completion interval.

\section{SURGING FLOW}

Wells in the SSGF have maximum production flow rates of 800 to $1000 \mathrm{gpm}$. The wells are normally operated at below-maximum flow rate, which reduces flashing-induced scaling and surging. All SSGF wells have a tendency to surge during production. Fluid-pressure variations at reservoir depth, measured during steady flow from wells Magmamax 1 (MM1) and Magmamax 2 (MM2) reflect this oscillatory surging. The exact cause of the surging is not very well understood. Further long-term flow tests with controlled flow rates may explain whether surging is a transitory phenomenon or an inherent characteristic of fluid production from the geothermal reservoir. 
TEMPERATURE OF PRODUCED BRINE AND STEAM

The temperature of the fluids produced from the wells supporting the GLEF is rather insensitive to variations in production flow rate. Following an initial warm-up period, fluid production temperatures range between 400 and $437^{\circ} \mathrm{F}$ for flow rates of 200 to $800 \mathrm{gpm}$. The maximum production temperature usually occurs at flow rates between 400 and $600 \mathrm{gpm}$. Below $200 \mathrm{gpm}$, temperatures tend to fall off significantly. The minimum sustainable flow for wells near the GLEF is about $100 \mathrm{gpm}$.

The temperatures of fluids produced from MMI and Woolsey Well 1 (WWI) during numerous production cycles at the GLEF from May 3, 1976 to April 13, 1978 are shown in Fig. 8. The temperature at WWl increased after the well was deepened from 2400 to $3500 \mathrm{ft}$ (between about 200 and 300 days). An unexplained increase in temperature at MMI followed a seven-month lapse in production from the well.

Static temperatures in MMI are 20 to $40^{\circ} \mathrm{F}$ higher than in WWl. A review of static temperature and pressure profiles and other facts about the two wells provides no reason for the differences between them in production and static temperatures. MMl must simply be completed in a hotter part of the geothermal reservoir.
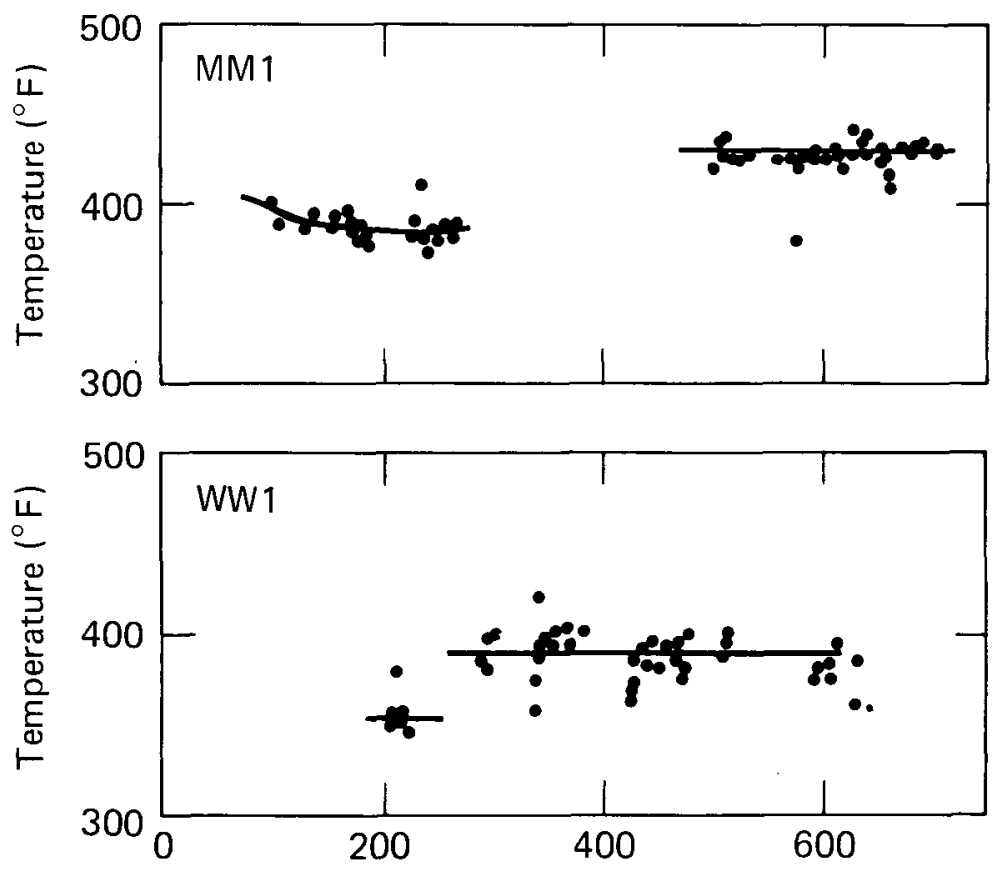

FIG. 8. Wellhead temperatures of brine and steam produced from MMl and WWl between May 3, 1976 and April 13,1978 .

Time from May 3, 1976 (days) 
RETURN TO EQUILIBRIUM AFTER FLOW

Production from geothermal wells is stopped by closing the wellhead valve. When flow stops, the single-phase brine column in the well cools and contracts, the liquid surface falls below the ground surface, and a vacuum is created above the falling liquid. The well has "gone on vacuum" in the parlance of well technology. All the production wells near the GLEF react in this manner when their flow is shut off.

The brine produced from the geothermal reservoir is cycled through the GLEF, where it cools to some extent. It is then injected back into the reservoir through injection wells. When injection of the cooled brine into injection wells is stopped by closing the wellhead valve, the relatively cool brine in the wells "falls" down the well in response to the pressure decline in the injection zone at depth. A vacuum is created above the liquid surface in the well. In some wells the top of the brine column can be as much as $300 \mathrm{ft}$ below ground level. As the brine reheats to the static temperature profile of the well, the top of the liquid column will move up to within 50 to $100 \mathrm{ft}$ of ground level.

After a geothermal well has been used for production or injection, it requires a minimum of two months to reach the steady conditions necessary for its use as an observation well in reservoir hydraulic testing. Complete return to the static temperature profile can take as long as six months, depending on the duration and amount of production or injection.

\section{INSTRUMENTATION FOR RESERVOIR PRESSURE MEASUREMENT}

The hydraulic characteristics of a reservoir are usually evaluated by studying the changes in reservoir pressure caused by producing liquid from the reservoir or injecting liquid into it. For this study, commercially available pressure measuring instrumentation was modified for use in the hostile geothermal well environment.

Reservoir pressure change in geothermal wells is sensed most accurately at reservoir depth. In a production or injection well, sensing pressure changes at reservoir depth is essential. On the other hand, in static observation wells not being used for production or injection, fluctuations in the liquid level reflect changes in pressure in the reservoir at depth fairly 
accurately. Therefore, sensing pressure a relatively short distance below the liquid surface in an observation well may provide an adequate record of reservoir pressure variation.

A commercially available lubricator and line-wiper assembly was used to place pressure-sensing equipment into the geothermal wells. This equipment provides a seal around the small-diameter tubing, wire, or cable used to suspend pressure-sensing devices in the wells. The seal is necessary, particularly in wells operated at positive wellhead pressures. Figure 9 shows a simple lubricator and line-wiper assembly attached above a gate valve to a wellhead. The key feature of this assembly is the line wiper, a heavy-duty, hydraulically inflated, rubber packing gland that closes about the cable, wire, or tubing suspended in the well. The line wiper prevents leakage of fluid from the well during injection or production. The lubricator also serves as a holding chamber for pressure-sensing devices before they are

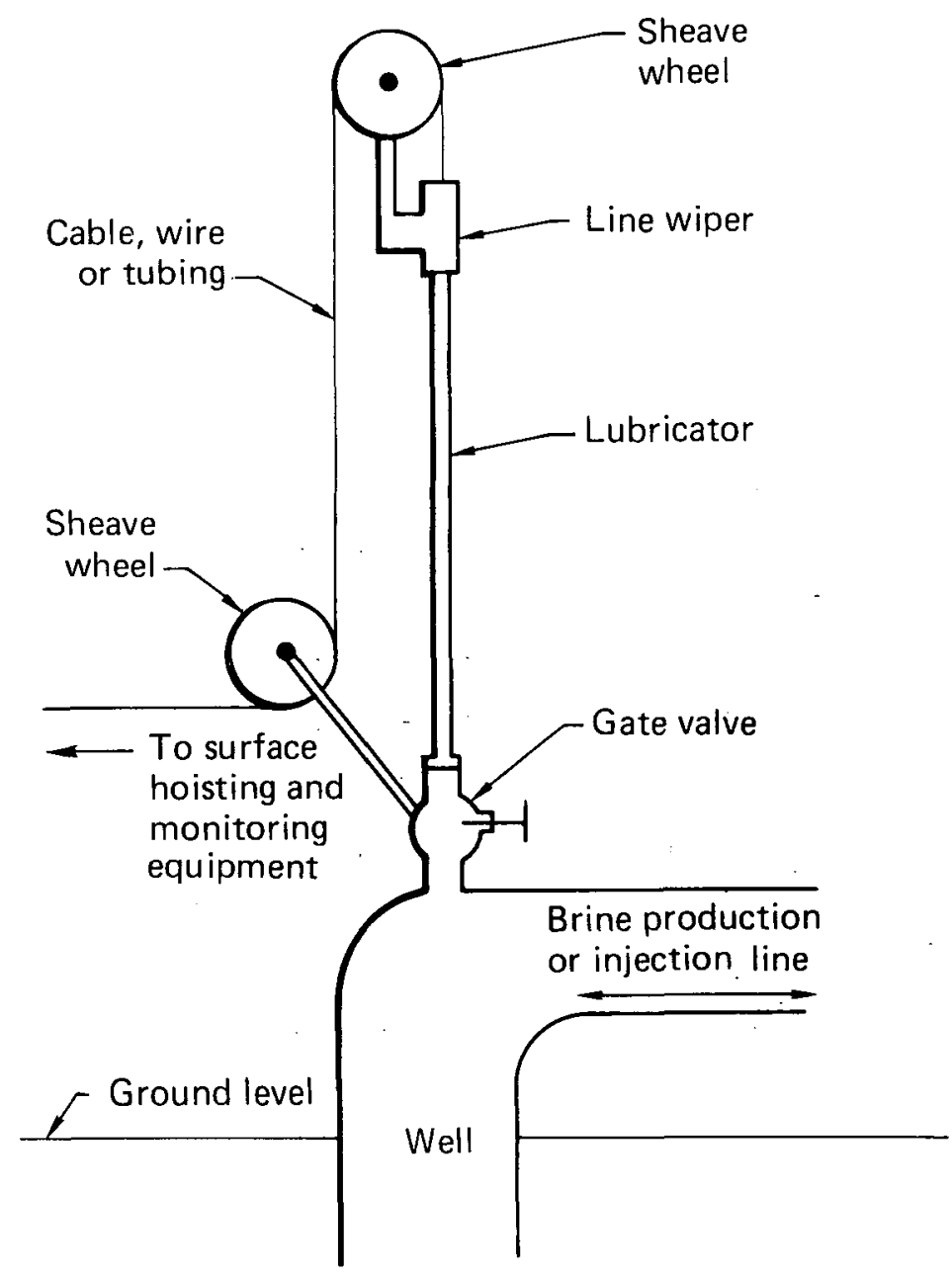

FIG. 9. Wellhead lubricator and line-wiper assembly. 
inserted into the well and after they are removed from the well. Pressuresensing devices must be sized to fit into the lubricator and to clear the wellhead gate valve and other constrictions in well plumbing.

It was necessary to modify existing pressure-sensing equipment to cope with the hostile environment at reservoir depth. The brine is hot ( 390 to $570^{\circ} \mathrm{F}$ ) and very corrosive, with more than 200,000 ppm total dissolved solids. These conditions accelerate the deterioration of support cable, wire, or tubing used to suspend pressure-sensing devices and lead to rapid failure of downhole electrical systems and of protective seals in downhole instrument packages.

\section{DIRECT PRESSURE MEASUREMENT}

Direct reservoir-pressure measurement relies on placement of a pressure gauge in a well at the depth at which pressure sensing is desired. HewlettPackard and Paroscientific quartz pressure gauges were adapted for use in the hostile reservoir environment and used in the well tests. Both the HewlettPackard gauge and the Paroscientific gauge have resolutions of about 0.01 psi. A Kuster pressure gauge was used to obtain static temperature and pressure logs.

\section{Hewlett-Packard Quartz Pressure Gauge}

A commercially available Hewlett-Packard (HP) quartz pressure gauge, packaged for use in wells by Gearhart-Owen, Inc., was modified for use in geothermal wells. This gauge is about $1 \mathrm{in}$. in diameter and is operated in conjunction with an integral temperature sensor. The gauge and temperature sensor are suspended in a well by a 3/16-in.-diameter coaxial cable, which provides electrical connections between surface and downhole electronics. The pressure gauge has quartz reference and sensing crystals in separate oscillator circuits. The frequency of the reference oscillator is fixed, while the frequency of the sensing oscillator is determined by the pressure acting on the sensing crystal. The absolute pressure at the location of the gauge is determined, using the difference in frequency between the sensing and reference oscillators and the temperature measured by the thermal sensor. Laboratory calibration provides the relationship between pressure, temperature, and difference in oscillator frequency. 
Because the downhole electronics package of the HP gauge fails at temperatures above $280^{\circ} \mathrm{F}$, it is unsuitable for use at reservoir depth in the SSGF, where temperatures can be 390 to $570^{\circ} \mathrm{F}$. Another problem is that the two quartz crystals must be at the same temperature for accurate pressure determination, but because their masses are different they are likely to be at different temperatures if the downhole package is changing temperature rapidly, and erroneous frequency differences will be recorded. Thus the HP gauge is not well suited for pressure measurement in thermally unstable wells, such as a production well is during its start-up or shortly after shutdown.

Other limitations are imposed by the effect of corrosive brine on electrical connections and seals of the HP gauge. The electrical connection with the coaxial support and conductor cable in the Gearhart-Owen cablehead assembly was particularly susceptible to attack by the brine. The connection was successfully isolated from the brine by injecting the cablehead with insulating grease (a blend of completely halogenated chlorofluorocarbons supplied by Halocarbon Products Corporation). With the connection in the cablehead assembly thus isolated, the HP gauge was used to measure pressure in Magmamax 3 (MM3), Magmamax 4 (MM4), and WWl for up to 60 days at temperatures from 180 to $280^{\circ} \mathrm{F}$. The details of the Gearhart-Owen cablehead assembly and a general view of the temperature sensor and HP quartz pressure gauge in the Gearhart-Owen package are shown in Fig. 10.

The o-ring seals in the package containing the HP pressure gauge deteriorate in the geothermal well environment. Because no seal material better than the normal Viton was found, new O-rings were installed each time the package was removed from a well.

The HP quartz pressure gauge was used successfully in environments where the temperature was less than $280^{\circ} \mathrm{F}$. In MM4 and WWl, used as observation wells, the gauge was placed above $500 \mathrm{ft}$, where temperatures were only 180 to $212^{\circ} \mathrm{F}$. The gauge was placed at reservoir depth $(2650 \mathrm{ft})$ in MM3 while the well was being used for reinjection of spent brine, which was at only $185^{\circ} \mathrm{F}$ at reservoir depth in the well. Injection pressures and the pressure decline following cessation of injection were measured. The reservoir injection interval in the well (2600 to $2800 \mathrm{ft}$ ) did not reheat until a week after injection flow had stopped. The fluid in the well above the injection zone reheated more rapidly, however, and the coaxial cable shorted out three days after cessation of injection. Further, the HP gauge was rendered inoperative by thermal damage in the course of being removed from MM3. The instrument 


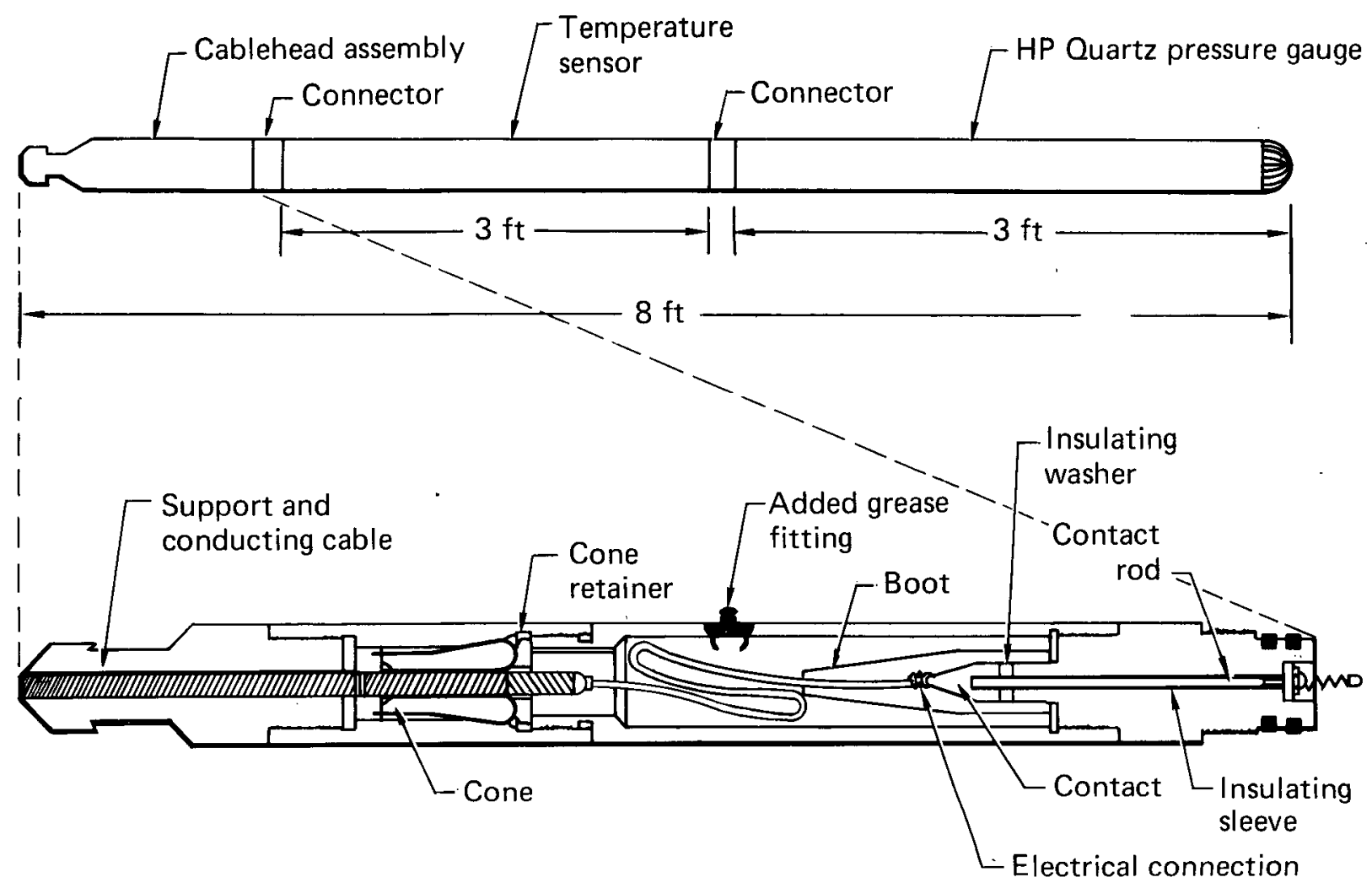

FIG. 10. A general view of the temperature/pressure sensing tool and details of the modified Gearhart-Owen cablehead assembly.

simply was left too long in the well after the injection of spent brine was stopped.

Paroscientific Quartz Pressure Gauges

A single-crystal quartz pressure gauge produced by the Paroscientific Corp. was adapted for reservoir pressure measurement. This pressure gauge is provided by the supplier in two configurations: the basic gauge, which is not designed for direct reservoir pressure measurement but is ideal for remote pressure measurement, and a second gauge packaged in a cylindrical watertight case designed to be submerged. To adapt this second gauge for geothermal work, a stainless steel cablehead assembly was built to provide a strong mechanical connection between the cable and the pressure gauge and to protect the electrical connection between the two from brine intrusions (Fig. 11). This cablehead assembly is filled with fluorocarbon grease to protect the electrical connections from the brine. (A cone-type cable retainer similar to 
Cable-pressure-

gauge electric

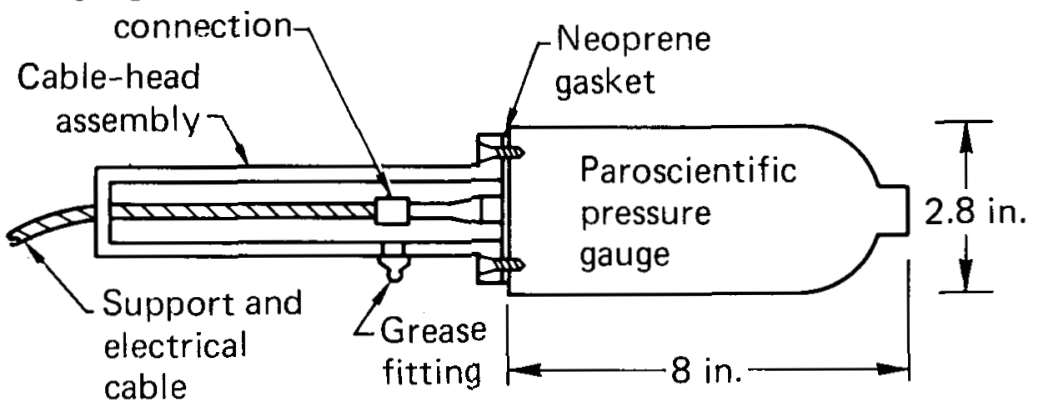

FIG. 11. Paroscientific pressure gauge and cablehead assembly.

that used in the Gearhart-owen cablehead assembly is used to provide mechanical connection.) A three-conductor armored cable is used with the Paroscientific pressure gauge.

The Paroscientific pressure gauge has essentially the same temperature Iimitations as the HP pressure gauge. The quartz crystal is part of an oscillator whose frequency depends on the pressure exerted on the crystal. Pressure is determined from the output oscillator frequency and appropriate calibration data.

Sinclair 3 (SN3) and Elmore 3 (EL3) were instrumented as observation wells with the submersible Paroscientific pressure gauge. The gauge was placed $150 \mathrm{ft}$ below the liquid surface in each well and pressure was successfully monitored from May thrôugh September 1978.

\section{Kuster Pressure Gauge}

The Kuster pressure gauge uses a Bourdon-tube pressure transducer mechanically linked to a clock-driven recording device. It comes as a well-logging tool about $3 / 4 \mathrm{in}$. in diameter and $5 \mathrm{ft}$ long that is suspended in a well on $0.094 \mathrm{in.} \mathrm{diameter} \mathrm{wire} \mathrm{line,} \mathrm{and} \mathrm{is} \mathrm{usually} \mathrm{operated} \mathrm{with} \mathrm{a}$ mechanical recording temperature sensor. The Kuster gauge was not used for well tests because of $i$ ts low resolution ( 1 to 5 psi) and short clock running time ( 3 to $12 \mathrm{hr}$ ). This instrument was used primarily to obtain static pressure and temperature logs in the geothermal wells.

\section{REMOTE PRESSURE MEASUREMENT}

Remote pressure-measurement systems are commonly used in geothermal, oil, and gas wells. With these systems, pressure changes at depth in the wells are 
transmitted to the surface by a column of light fluid, usually nitrogen or helium. Wellbore pressure is determined by measuring the pressure of the transmission fluid using a mechanical or electromechanical pressure gauge at the surface. The fluid-pressure transmission column is normally contained in a small stainless steel tube (0.094 to $0.125 \mathrm{in}$. in diameter) that is lowered into a well to reservoir depth. A pressure-sensing chamber is attached to the bottom of the pressure-transmission tube. The chamber is a stainless steel gas-filled tube, 1 to $2 \mathrm{in}$. in diameter and 10 to $20 \mathrm{ft}$ long. The interface between the wellbore fluid and the pressure-transmission fluid occurs near the lower end of the pressure-sensing chamber, which has sufficient volume to minimize any vertical movement of the interface that might be caused by changing reservoir pressure.

\section{Sperry Sun Pressure-Transmission System}

A Sperry Sun pressure-transmission system (Fig. 12) was used in the first tests in the geothermal wells near the GLEF. The gas-column pressure is

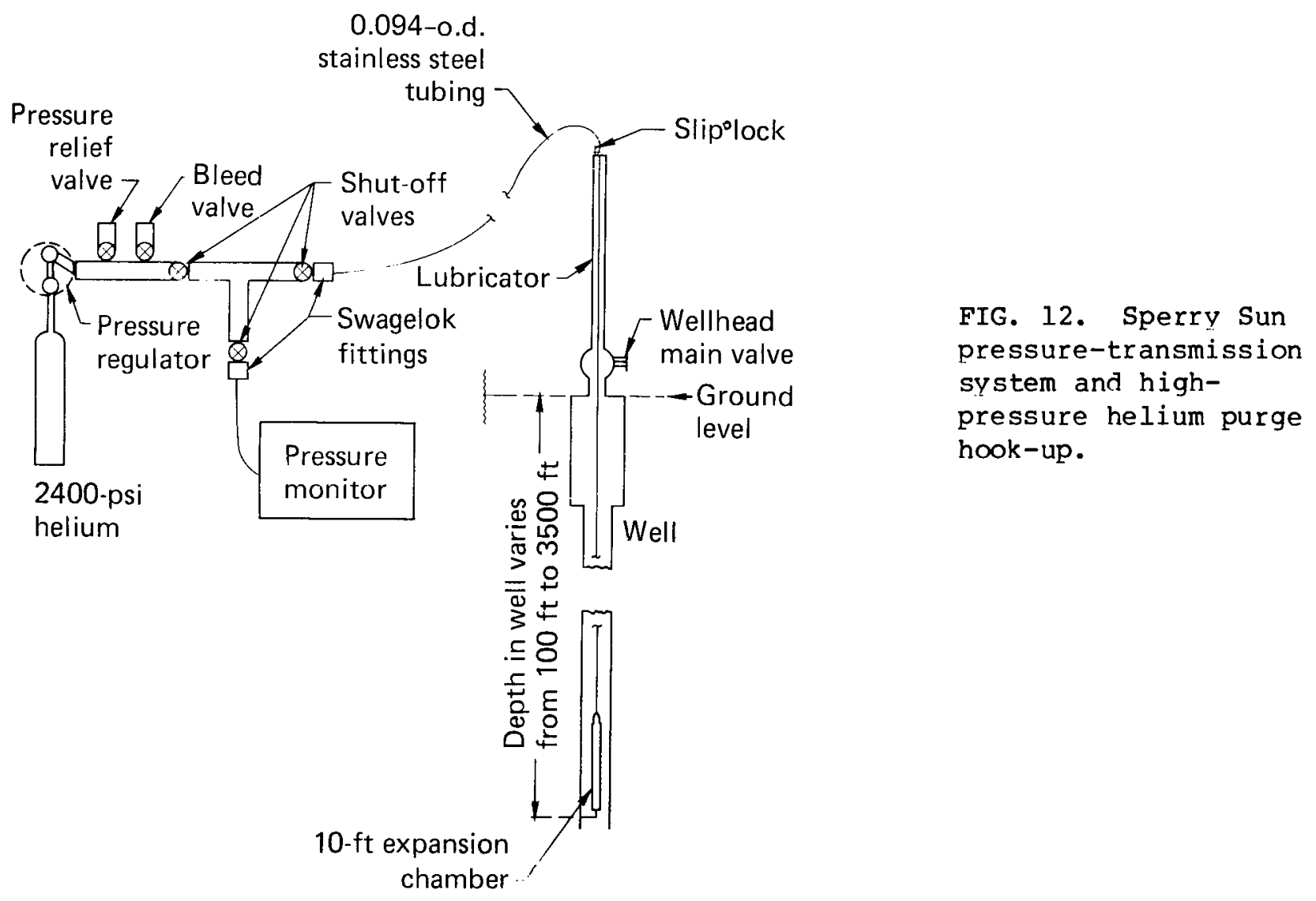


measured with an optical-mechanical pressure transducer. Two Sperry Sun transducers were tried: a pressure monitor (0-to-5000-psi range) with resolution of about $5.0 \mathrm{psi}$ and a pressure recorder (0-to-1000-psi range) with resolution of about $0.1 \mathrm{psi}$. The pressure monitor had insufficient resolution and an inadequate data output format for use in the well tests. The pressure recorder, which provided a printed output of time and pressure in addition to a visual display, was convenient and had sufficient resolution for observationwell pressure measurement.

Although the Sperry Sun system is not vulnerable to high temperatures, its performance is severely affected by temperature variations, both in the well and at the surface. Temperature transients in the wells under flowing conditions and diurnal temperature variations at and near the surface cause large pressure changes in the gas column. The optical-mechanical pressure transducer at the surface is also sensitive to diurnal temperature changes and had to be located in a controlled temperature environment. Under the best of conditions during well testing, the temperature sensitivity of the Sperry Sun system was manifest in a 0.1-to-3.0-psi oscillation superimposed on the measured reservoir pressure variation.

The corrosive effects of the brine impose the most severe limitations on the commercially available pressure-transmission systems. A 300-series stainless steel and an iron-chromium-molybdenum alloy are the materials normally used for pressure-transmission tubing. Tubing made of these materials suffered from stress-corrosion cracking and failed repeatedly in the geothermal wells. The stress-corrosion cracking of the tubing is more severe at higher temperatures. To avoid tubing failure, the Sperry Sun pressure-transmission system was installed only in nonflowing observation wells, with the pressuresensing chamber only 150 to $200 \mathrm{ft}$ beneath the brine surface. With this technique, the Sperry Sun system was used successfully to instrument MMl and MM4 as observation wells.

\section{An Improved Pressure-Transmission System}

An improved pressure-transmission system was designed and assembled to provide for measurement of wellbore pressure variation at reservoir depth in flowing geothermal production wells. The heart of the improved system is pressure-transmission tubing made of Hastelloy C-276 supplied by the Superior Tube Company. The outside diameter of this tubing is 0.130 in.; the inside 
diameter is $0.060 \mathrm{in.}$ The tubing is very malleable, was stored on a 10-1/2-in.-diameter drum reel, and moved in and out of the wells over 12-in. sheave wheels with no difficulty. A Paroscientific quartz-crystal pressure transducer was used instead of nitrogen or helium gas at the surface to measure pressure changes transmitted from reservoir depth through the Hastelloy tubing.

silicon oil is used instead of nitrogen or helium gas as the pressuretransmitting fluid in the improved system. Because this oil is denser than the gases, although less dense than the geothermal brine, a relatively small positive pressure is measured in the tubing at the surface under static equilibrium conditions. Under the same conditions, a system using helium or nitrogen would exhibit a greater surface pressure, very close to that at reservoir depth. Thus, the silicon-oil-filled system does not yield measurements of actual wellbore pressure at the depth of its sensing chamber, but it does faithfully sense and measure changes in pressure. The techniques of well-test analysis applied in this study require only pressure-change input, not absolute pressure values.

Silicon oil also has other advantages over gas as a pressure-transmission medium: with the oil, pressure changes are transmitted to the surface hydraulically and detected with less time lag; thermal transients cause smaller pressure changes in the oil column, resulting in less signal noise; and the smaller maximum pressure of the oil at the surface allows the use of pressure transducers with smaller pressure range and greater resolution.

Wellbore temperature transients are a problem with this system only on initial start of a production well. To avoid this problem, the well is allowed to flow at a low rate $(200 \mathrm{gpm})$ until it is at its normal operating temperature before it is opened to its normal operating flow rate (400 to $800 \mathrm{gpm}$ ). Another problem is that spurious pressure changes can occur when the sun heats the excess Hastelloy tubing on its reel at the surface. This problem was eliminated by simply insulating the tubing reel with a fiberglass blanket.

An oil-filled pressure-sensing chamber, weighted by a 30-1b sinker bar, is. connected to the bottom of the Hastelloy pressure transmission tubing. Contact between the silicon oil and the brine is assured by four 1/16-in.diameter holes at the lower end of the sensing chamber. Both the chamber and sinker bar are less than 1 in. in diameter. In both production-well tests in which this system was used, the sensing chamber was installed in the wellbore through 1.3-in.-diameter tubing that extended to the production zone at reservoir depth. This tubing, which was perforated to expose the pressure 
chamber to reservoir pressure, protected the pressure-sensing equipment from damaging contacts with the wellbore casing and, along with the sinker bar, prevented the pressure chamber from migrating upward with the flow of brine in the wellbore.

The improved system successfully measured reservoir pressure changes during production in MMI and MM2. Dow Corning 200 silicon oil of 10-cp viscosity worked nicely as a pressure transmitting medium. The Hastelloy pressure-transmission tubing was installed in MM2 for 60 days and in MM1 for 100 days without failure or visible damage. The tubing is extremely resistant to corrosion.

GEOTHERMAL WELL TESTS

The geothermal wells of primary interest in the well tests were the Magmamax and Woosley wells (Fig. 1). MMl and WWI are the production wells for the GLEF. MM3 was the primary injection well for disposal of spent brine unti]. July 1978; since then, MM2 has been used for injection of brine. MM4 was designed and used as an observation well.

The drawdown of pressure during production and pressure buildup after production ceased were measured at reservoir depth in MM1 and MM2. Flowinginjection pressures and pressure falloff following an injection period were measured at reservoir depth in MM3. (Some of the injection pressure data for MM3 is given in Appendix B.) Long-term observations of pressure transients were conducted in MM4, Elmore No. 3 (EL3) and Sinclair No. 3 (SN3). These observation wells were instrumented to measure pressure transients in the geothermal reservoir resulting from brine production and injection. Additional tests were conducted between MMI and.WWI, using one as a production well and the other as an observation well.

INJECTION WELL TESTING

Three surveys of pressure dropoff following injection episodes were conducted in MM3 in conjunction with the most active period of injection into the well, from May 3, 1976 to April 13, 1978. All three tests recorded pressure changes at a depth of approximately $2650 \mathrm{ft}$. The first two surveys, December 14, 1976 and March 3, 1977, were conducted by Magma Power Company 
using the relatively low-resolution Kuster pressure-logging tool. Although the results from these dropoff tests gave a qualitative indication that the injection interval was moderately permeable, no calculation of permeability values was possible. Pressure resolution was too poor to allow determination of the slope of the straight-line portion of the graph of pressure vs the logarithm of time. Without the slope, no calculations of permeability could be made.

The third survey was begun on April 13, 1978, using the high-resolution Hewlett-Packard quartz pressure gauge. This survey was specifically designed to assist in determining the extent and type of well impairment in MM3. The dropoff test was conducted by lowering the HP gauge $2650 \mathrm{ft}$ into MM3 during an iniection period several days before shut-in. The instrument was installed inside a protective 2-in. pipe which extended $2800 \mathrm{ft}$ into the well. The pipe was perforated from 2600 to $2800 \mathrm{ft}$ to enable the pressure gauge to sense pressure adjacent to the injection zone.

The injection cycle prior to shut-in was relatively stable, with an average continuous injection flow of $400 \mathrm{gpm}$. This consistency provided excellent conditions for obtaining high-quality data. Pressures were recorded in MM3 for several days prior to shut-in to obtain a pseudo steady-state overpressure baseline. At shut-in, the dropoff in pressure at the level of the injection zone was recorded in detail. Pressure was measured until April 16, 1978, when reheating of the wellbore necessitated removal of the pressure gauge.

The pressure declines in the three surveys are compared in Fig. 13. Note that the third survey is documented with more data than the first two. Wellbore storage effects end in all three at about 100 minutes after shut-in. Only the third survey was carried out long enough after cessation of wellbore storage effects to merit closer examination.

The pressure decline for the useful portion of the third survey, as shown in detail in Fig. 14, follows a definite linear semilogarithmic path from log time $=2.65(447 \mathrm{~min})$ to $\log$ time $=3.05(1122 \mathrm{~min})$. An earlier portion of the pressure decline apparently followed a somewhat steeper linear semilogarithmic path. Using the slopes of linear pressure decline of Fig. 14 and brine viscosity values of 0.1 to $0.2 \mathrm{cp}$, gives a reservoir permeability ranging from 250 to $1000 \mathrm{md}$. It had been determined that a 200-ft-thick interval in the reservoir was accepting the flow injected into MM3. Two linear portions of pressure decline, separated by an inflection as in Fig. 14, are characteristic of 


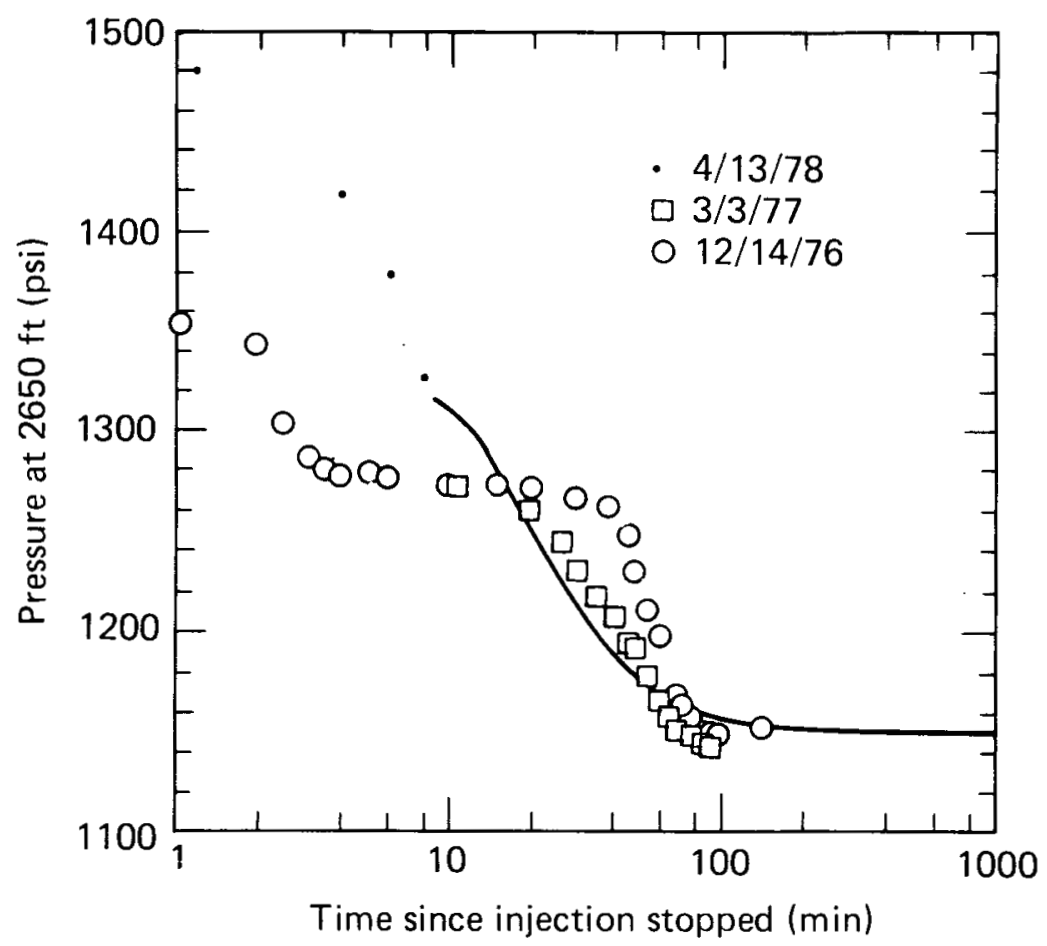

FIG. 13. Pressure dropoff following injection into MM3.

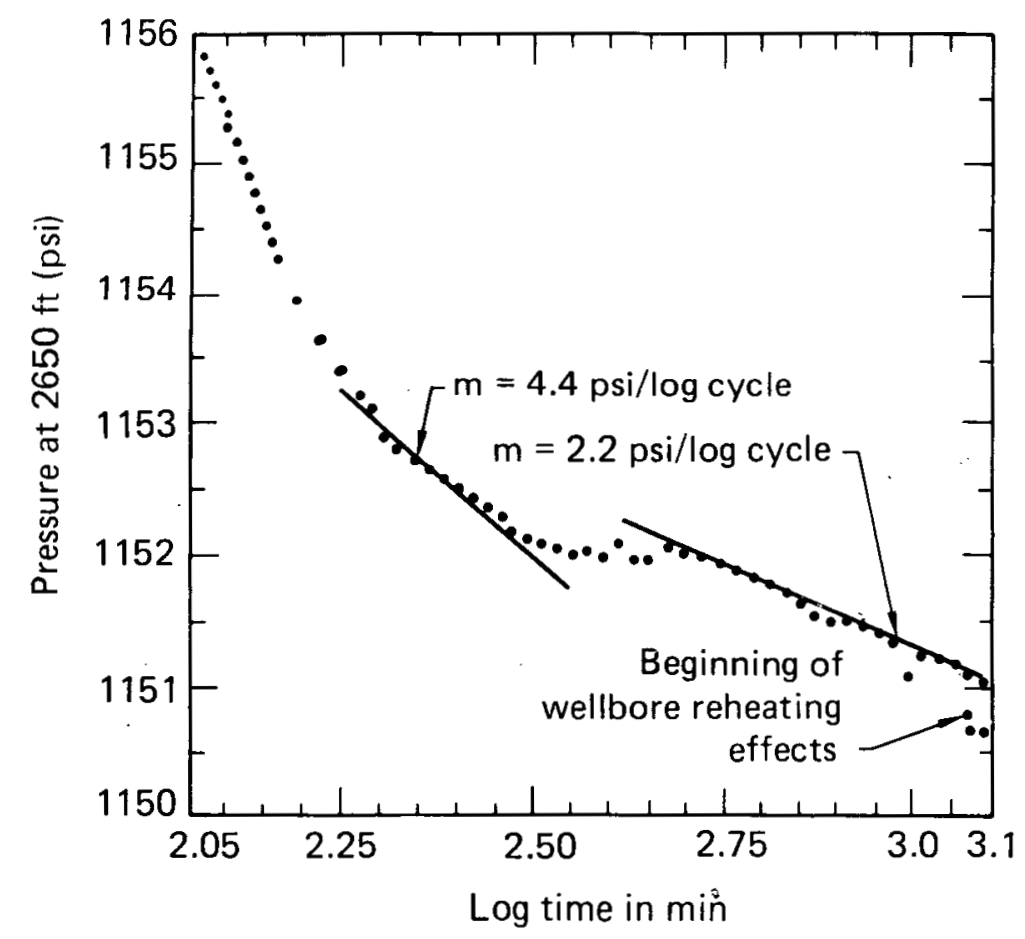

FIG. 14. Details of the MM3 dropoff test of April 13, 1978, from 112 to $1280 \mathrm{~min}$ after injection stopped. 
pressure response in a reservoir where fluid flow has important components through both the rock matrix and fractures that transect the matrix. ${ }^{11}$

Evidence from drill chips and cores indicates that intergranular porosity in the geothermal reservoir rock is complemented by fracture porosity. ${ }^{3}$ Analysis of the pressure dropoff data from MM3 indicates that the reservoir injection interval, away from the well, is moderately permeable and sustains combined fracture and matrix flow.

The progressive impairment of the hydraulic efficiency of MM3 was quantified by estimating values of the dimensionless skin factor ${ }^{12}$ of the well for the three dropoff surveys. The skin factor is given by

$$
S=1.1513\left[\frac{P_{1 h r}-P_{w f}(\Delta t=0)}{m}\right]-\log \left(\frac{k}{\phi \mu C_{t} r_{w}^{2}}\right)+3.2275,
$$

where

$$
\begin{aligned}
& \mathrm{P}_{\text {Ihr }} \quad=\text { pressure on straight-line portion of semilog plot } \mathrm{l} \text { hr after } \\
& P_{\text {wf }}(\Delta t=0)=\text { flowing bottom-hole pressure just before starting a } \\
& \text { transient well test, psi. } \\
& r_{w} \quad=\text { wellbore radius, } f t .
\end{aligned}
$$

Using $m=2.2 \mathrm{psi} / \log$ cycle of time, $k=1000 \mathrm{md}, \phi=20.8, \mu=0.2 \mathrm{cp}, \mathrm{c}_{\mathrm{t}}=$ $1.4 \times 10^{-5} \mathrm{psi}^{-1}$ and $\mathrm{r}_{\mathrm{w}}^{2}=0.11 \mathrm{ft}^{2}$, skin factors of 90,158 , and 171

were calculated for the first, second, and third dropoff surveys, respectively. These values are much greater than the normal range of values for skin factor and attest to progressive impairment of MM3.

The MM2 production test was conducted in April and May of 1978. The flow rate was 400 to $800 \mathrm{gpm}$. The energy of the hot brine was dissipated through a steam-water separator and an atmospheric flash tank installed next to the MM2 wellhead. Approximately $1 \times 10^{7}$ gal of brine were produced during a cumulative operating time of $331.4 \mathrm{hr}$. The production interval in the MM2 well was from 3800 to $4300 \mathrm{ft}$.

The MM2 test was originally planned as a continuous production sequence with three different flow rates over a three-week period. The flow at each 
rate was to take place in equal-length episodes and increase step-wise from 400 to 600 to $800 \mathrm{gpm}$. The actual MM2 test consisted of eight separate production periods of unequal duration with flow rates ranging from 400 to $800 \mathrm{gpm}$. Figure 15 is a histogram of the actual production test. The discontinuous flow periods were caused by shutdowns made necessary by erosion of surface control valves and piping by sand produced from the well.

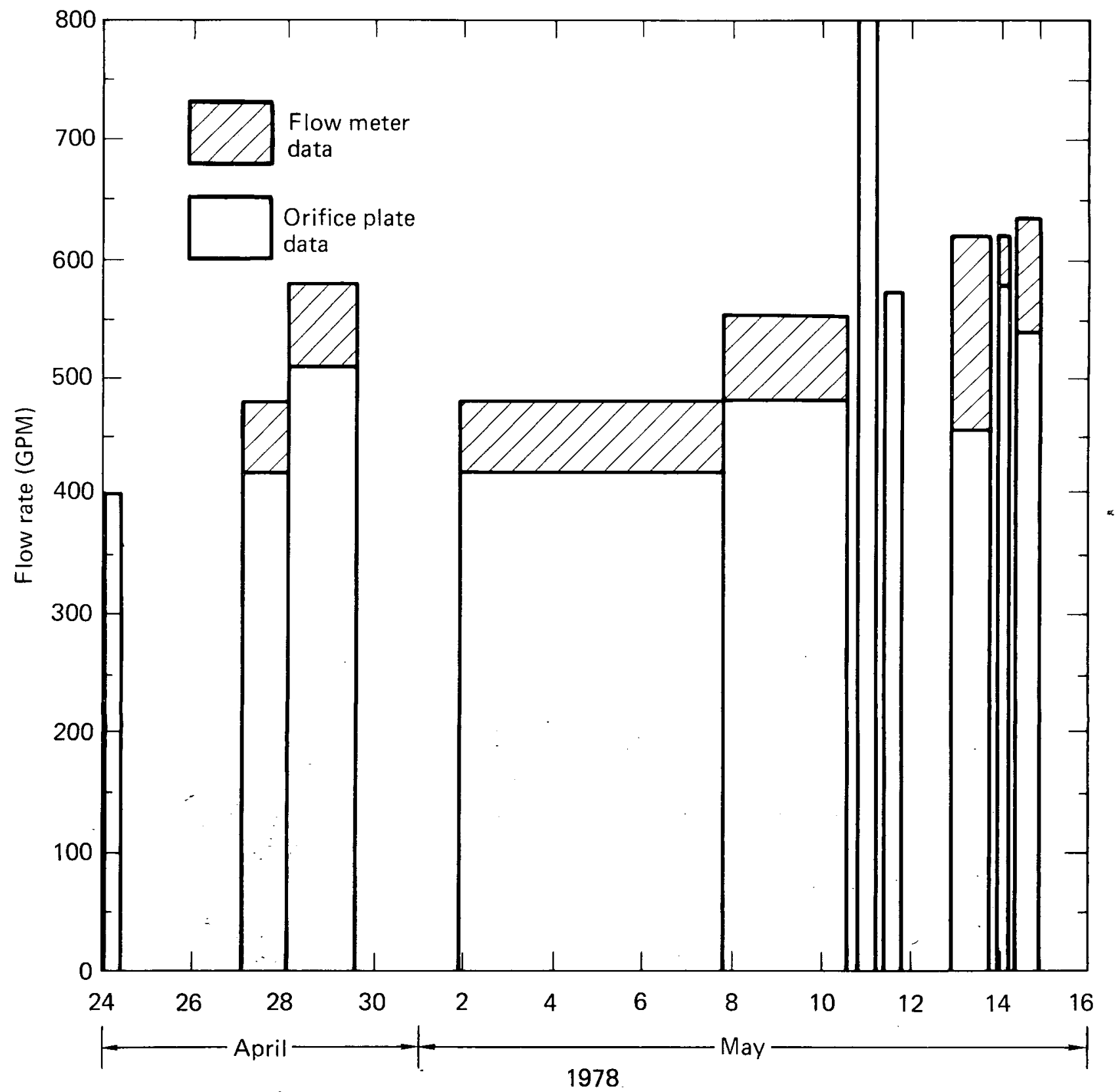

FIG. 15. Flow-rate estimates for the MM2 production test of April 24 to May 15, 1978. The total flow was $10.6 \times 10^{6}$ gal based on flow-meter data and $9.3 \times 10^{6} \mathrm{gal}$ based on or ifice-plate data. Total operating time was $331.4 \mathrm{hr}$. 
The Hastelloy C-276 pressure-transmission system, with 100-cp-viscosity silicon oil as the transmitting fluid and with an attached pressure-sensing chamber, was lowered to $3800 \mathrm{ft}$ inside a protective 1.3-in.-diameter pipe that extended to $3813 \mathrm{ft}$ and was perforated at various depths to allow for hydraulic communication. The protective pipe minimized buffeting and upwelling of the pressure transmission system during brine production.

The system functioned well, and a detailed record of pressure changes at reservoir depth was obtained (Fig. 16). Seven buildup and two drawdown surveys were obtained. Some of the buildup surveys lacked early time data because of unexpected well shut-ins resulting from surface equipment failure.

Table 1 gives the results of the drawdown and buildup tests. Note the increase in the calculated values of permeability between the April 30 and May 11 buildup surveys. This increase was caused by the removal of fill in the lower $150 \mathrm{ft}$ of MM2 and by reduction of formation plugging during brine production. Evidence from geophysical logs showed that many of the more permeable reservoir layers are within the bottom $150 \mathrm{ft}$ of the well. During the initial flow period for MM2, the fill at the bottom of the well prevented production from these permeable layers.

Because of noisy and erratic pressure fluctuations and the relatively short production periods, only two usable drawdown surveys were obtained. The

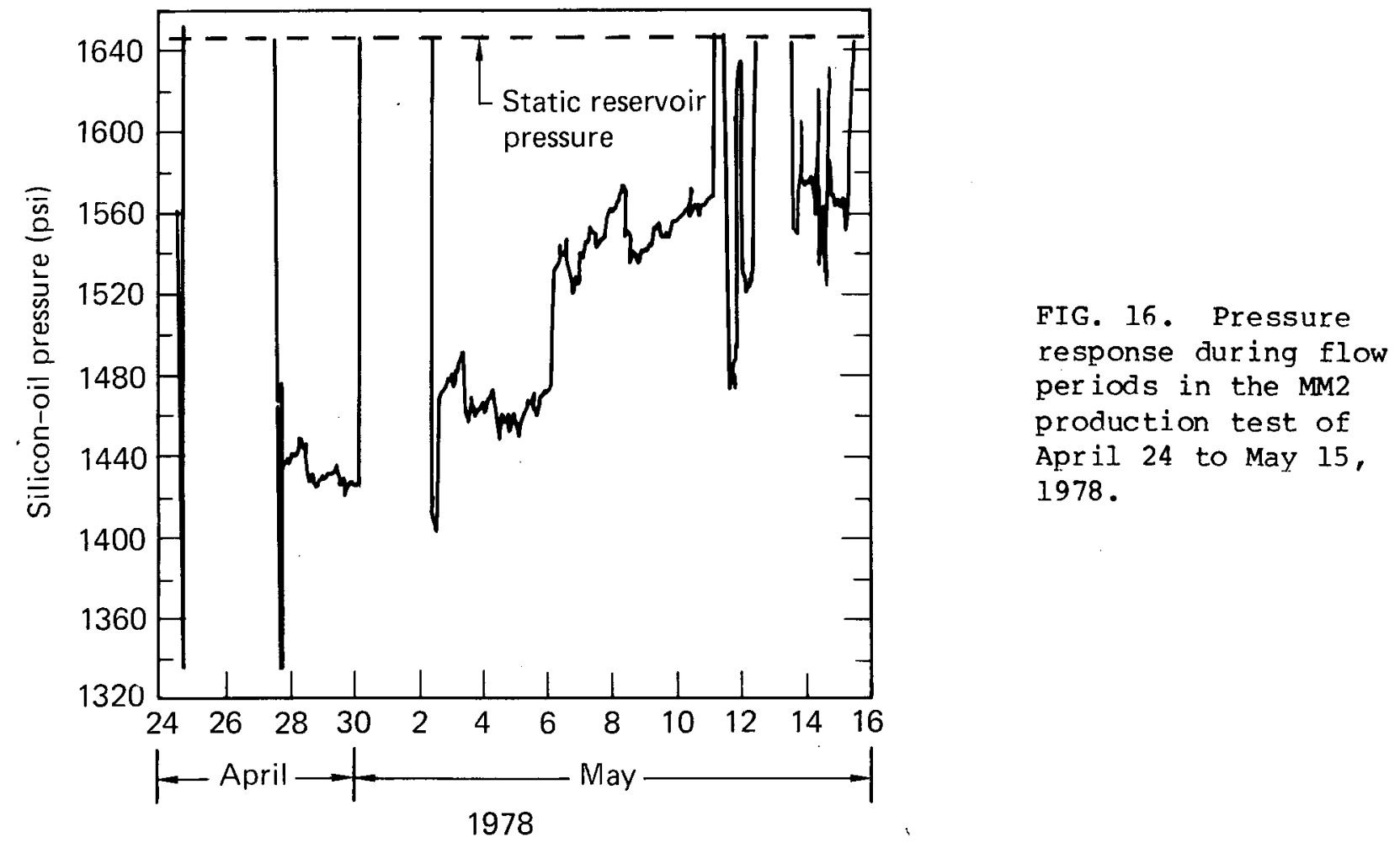


TABLE 1. Results of well tests in MM2, April 24 to May 15, 1978. (Formation thickness, $177 \mathrm{ft}$; fluid viscosity, $0.1 \mathrm{cp}$.

\begin{tabular}{lllccc}
\hline Date & $\begin{array}{c}\text { Test } \\
\text { type }\end{array}$ & $\begin{array}{l}\text { Start } \\
\text { time }\end{array}$ & $\begin{array}{c}\text { Flow rate, } \\
\text { gpm }\end{array}$ & $\begin{array}{c}\text { Semi log } \\
\text { slope, } \\
\text { psi/cycle }\end{array}$ & $\begin{array}{c}\text { Permeability, } \\
\text { md }\end{array}$ \\
\hline $4 / 30 / 78$ & Buildup & $01: 59: 00$ & 510 & 72.0 & 22 \\
$5 / 11 / 78$ & Buildup & $04: 20: 00$ & 552 & 27.7 & 63 \\
$5 / 11 / 78$ & Drawdown & $12: 15: 21$ & 200 to 800 & -10.5 & 60 \\
$5 / 11 / 78$ & Buildup & $21: 20: 10$ & 800 & 32.2 & 78 \\
$5 / 12 / 78$ & Buildup & $10: 11: 20$ & 574 & 32.5 & 56 \\
$5 / 14 / 78$ & Buildup & $10: 21: 30$ & 620 & 27.0 & 72 \\
$5 / 14 / 78$ & Buildup & $17: 53: 20$ & 620 & 27.0 & 72 \\
$5 / 14 / 78$ & Drawdown & $19: 02: 00$ & 540 & -20.5 & 83 \\
$5 / 15 / 78$ & Buildup & $10: 06: 18$ & 540 & 15.3 & 11 \\
\hline
\end{tabular}

May 14 drawdown is shown in Fig. 17. Permeability estimates from these two tests agree closely with estimates from the buildup tests.

The graphs of pressure buildup from the MM2 test all follow a similar and somewhat unique pattern (Figs. 18-21). They all have a hump in the pressure buildup beginning at 1 to $2 \mathrm{~min}$ and ending at $6 \mathrm{~min}$ after well shut-in. This hump is believed to have been caused by segregation of steam and brine in the wellbore after shut-in. This "steam-storage effect" ends at $6 \mathrm{~min}$ after shutin followed by the start of the semilogarithmic straight-line portion of the pressure $r$ ise at about $8 \mathrm{~min}$.

The value of $\mathrm{h}$ for the MM2 well was estimated on the basis of geophysical logs of the well. There appear to be 177 cumulative feet of permeable sand in the 500-ft-thick production zone of MM2. Sand layers included in this 177 feet have estimated permeabilities of at least $10 \mathrm{md}$. Sand and shale layers with less than 10-md permeability are assumed to produce negligible amounts of brine.

As shown by the performance of MM2 before and after the production test, its efficiency as a production or injection well was dramatically improved. Before April 24, 1978, MM2 was the stand-by injection well but there were only a few short periods of actual activity. During these short injection periods, 


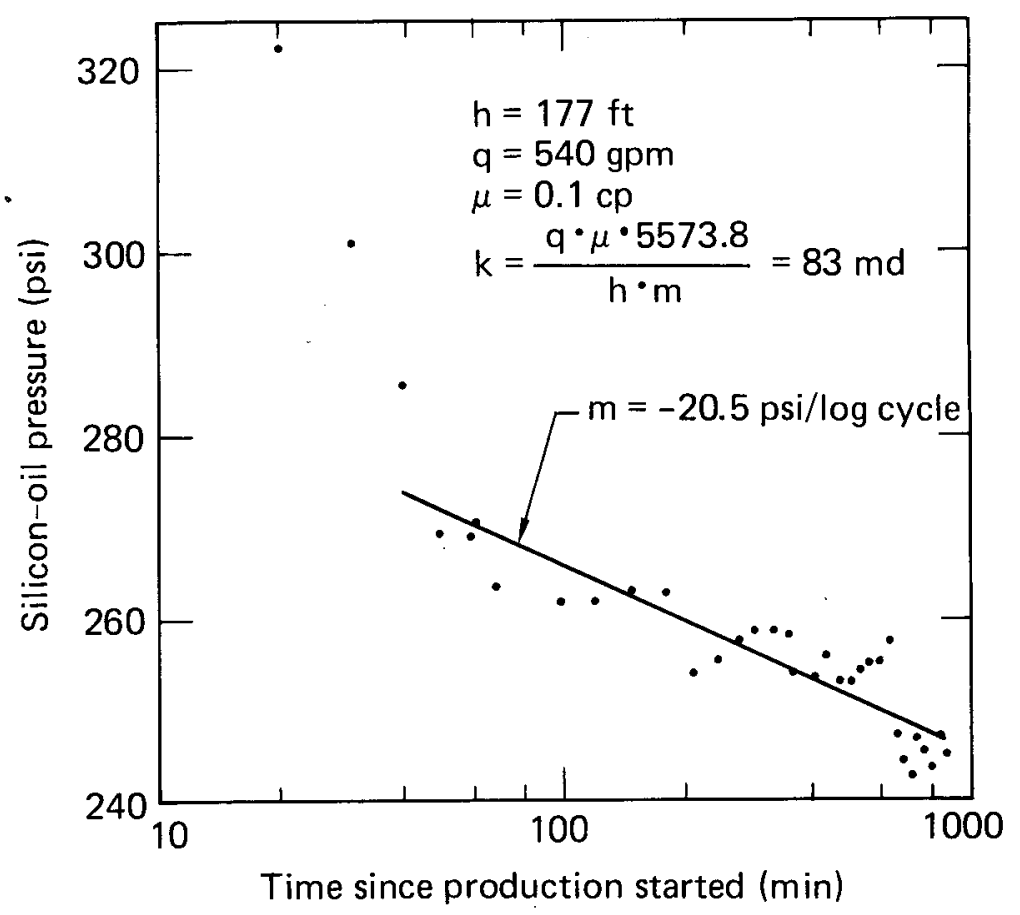

FIG. 17. Pressure drawdown in MM2 on May 14, 1978 .

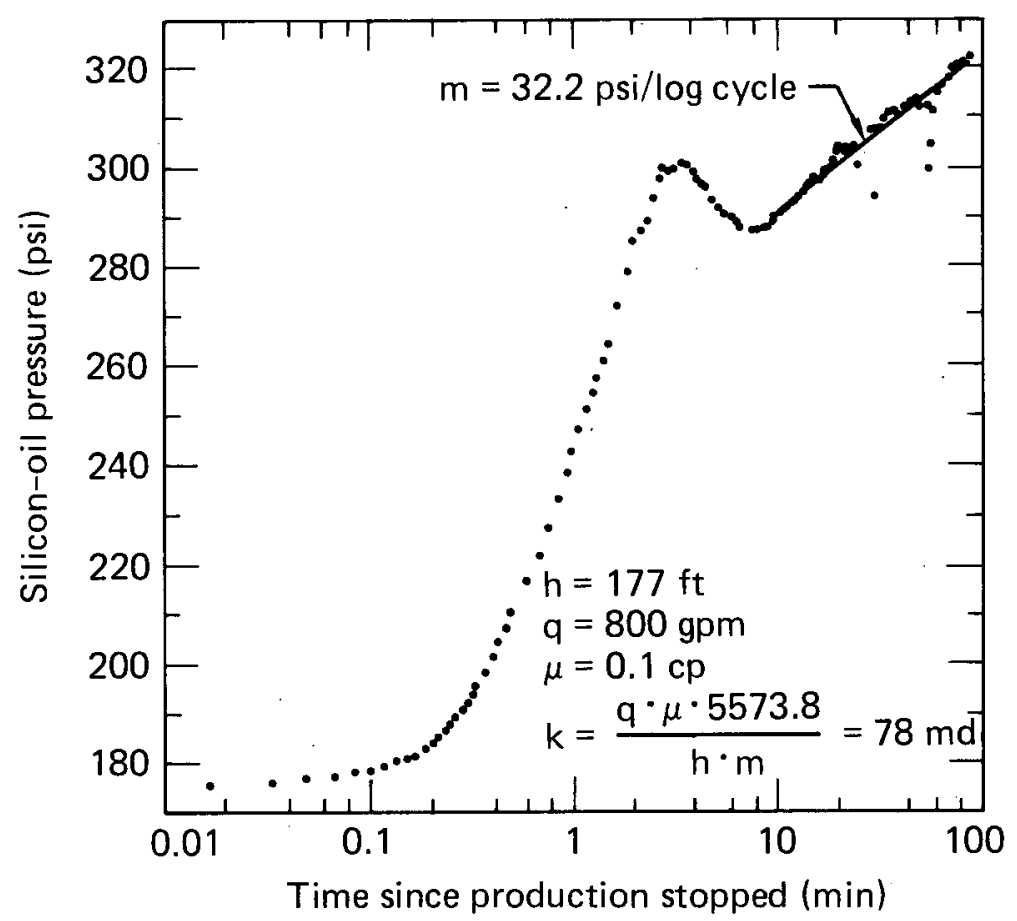

FIG. 18. Pressure buildup in MM2 on May 11, 1978 . 


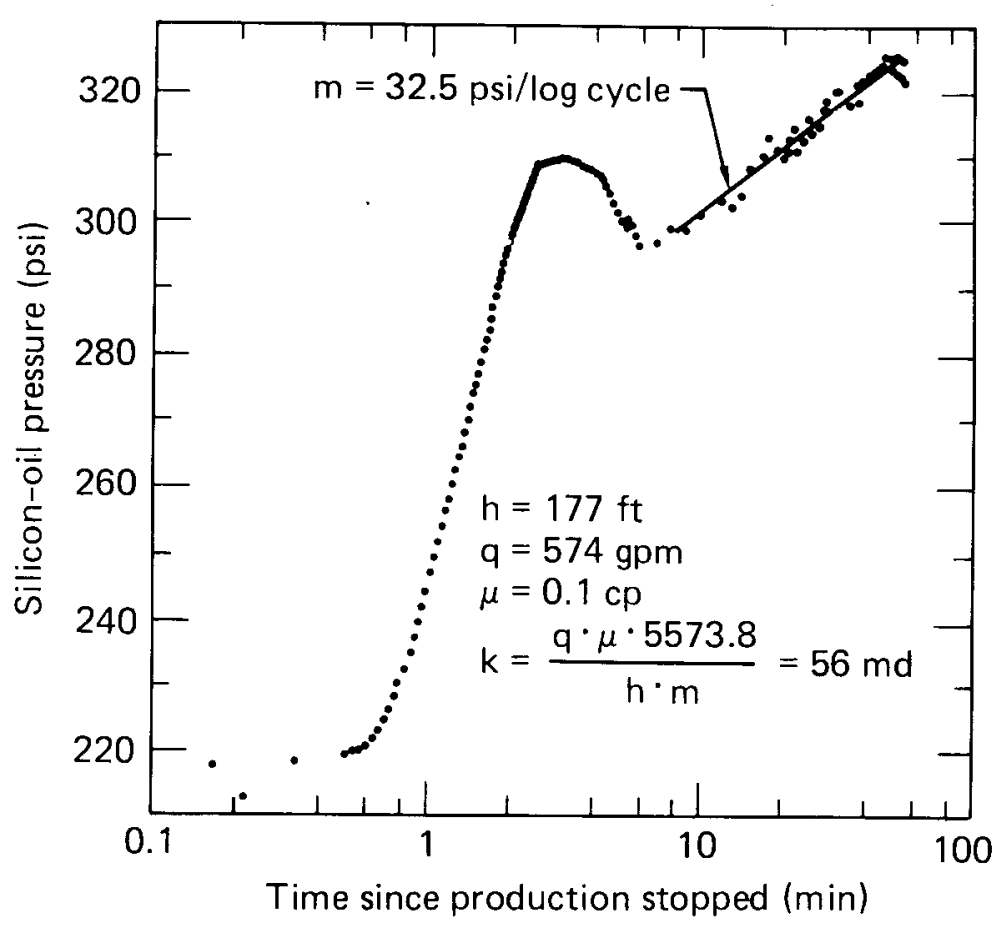

FIG. 19. Pressure buildup in MM2 on May 12, 1978.

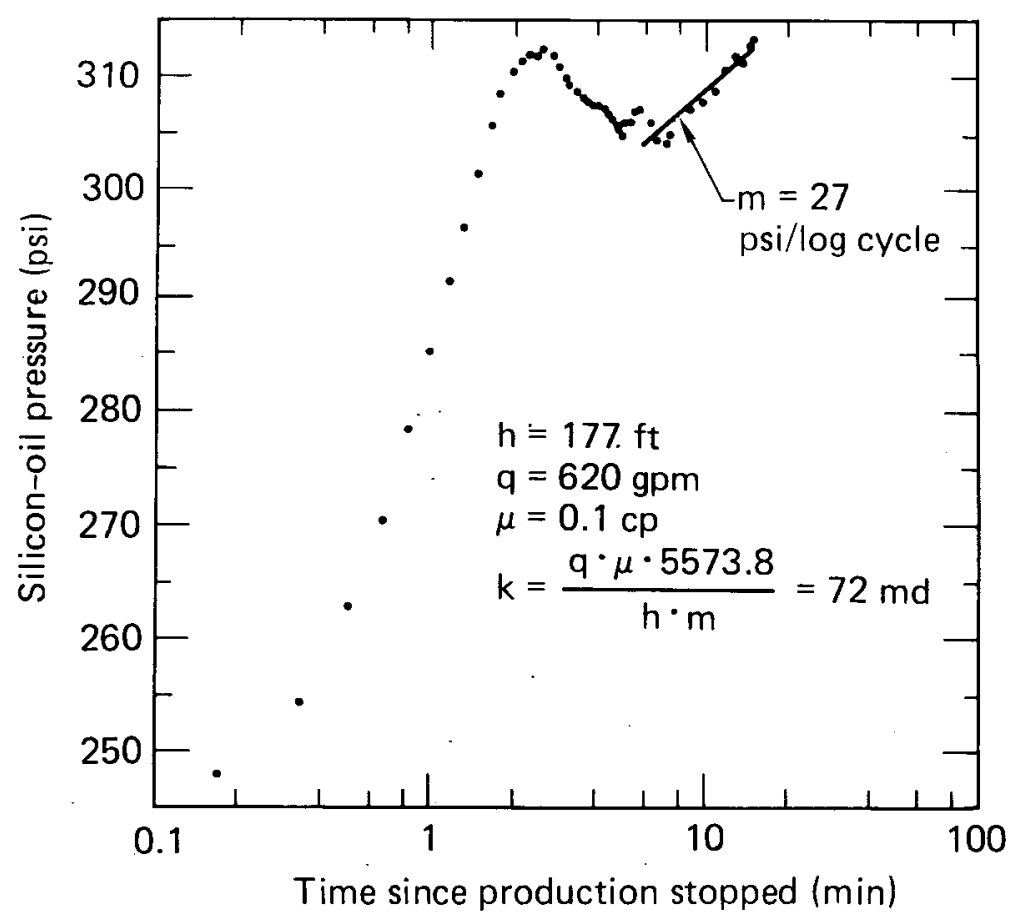

FIG. 20. Pressure buildup in MM2 starting 10:21:30 on May 14, 1978. 


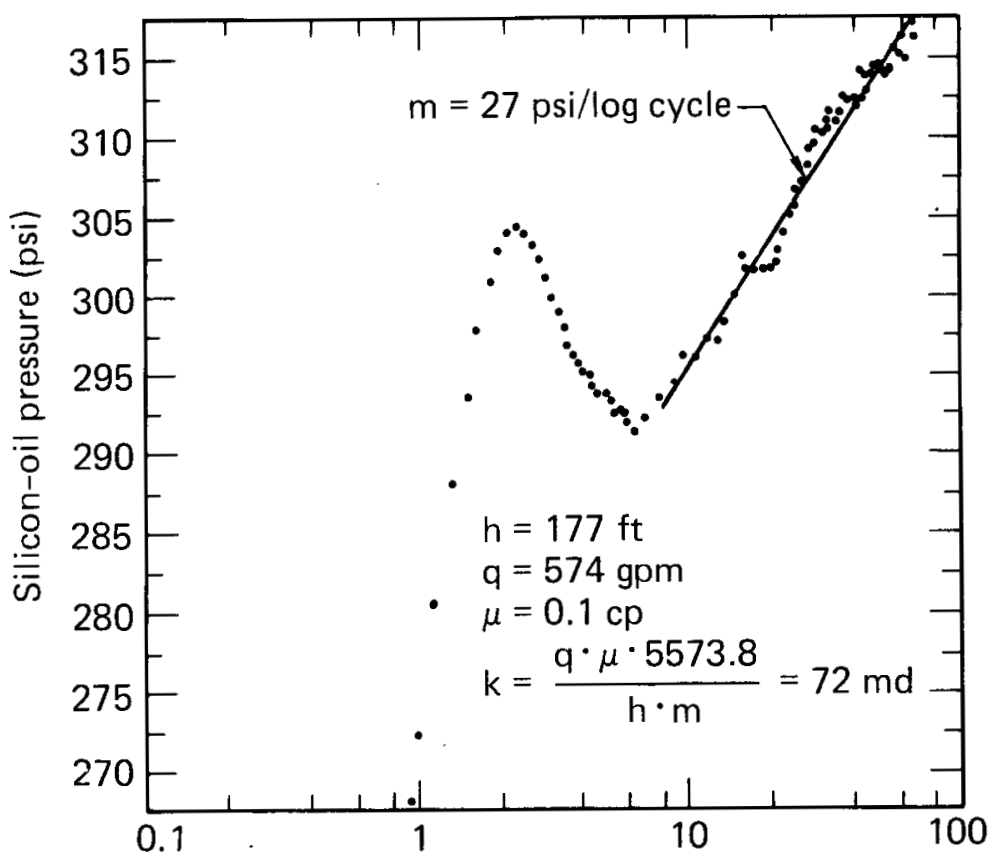

FIG. 21. Pressure buildup in MM2 starting at $17: 53: 20$ on May 14, 1978 .

Time since production stopped $(\mathrm{min})$

high wellhead pressures were required to dispose of brine flows of 400 to $600 \mathrm{gpm}$; MM2 had to be hydrofractured to cause it to accept flow. Following the production test, MM2 became the primary injection well and operated with negligible wellhead pressure during its first 1400-hr injection cycle. A series of production cycles was an excellent means of improving the injection efficiency of MM2.

PRODUCTION-WELL TESTING

MMI was twice instrumented for pressure transient well tests. The first time, in July 1977, MMI was used as an observation well for an interference test between MMI and WWI. The second period was from July 10 to September 24, 1978, while MMI was being used as the brine production well for GLEF operations.

The interference test between MMI and WWI was the first well test of the program. MMl was instrumented with a Sperry Sun pressure transmission system from June 24 to July 12, 1977. Pressure transients were recorded at the surface using the Sperry Sun pressure recorder. The pressure-sensing chamber was suspended at $200-\mathrm{ft}$ depth in the well. Tubing of Fe-26Cr-1Mo alloy filled with helium gas was used to transmit pressure changes to the surface. Pressure 
changes sensed at $200-\mathrm{ft}$ depth in the well were assumed to reflect reservoir pressure changes accurately.

Baseline pressure data was recorded for a week before the start of this test. Diurnal heating and cooling of the wellhead, tubing, and instruments resulted in a cyclic 24 hr pressure fluctuation of $0.3 \mathrm{psi}$, which complicated the analysis of the interference tests. Brine was produced from wWl at $600 \mathrm{gpm}$ from July 2 to July 5, 1977. The resulting drawdown in pressure observed in MMl is shown in Fig. 22. The diurnal pressure noise is evident in the figure. Total drawdown during the test was about 1 psi.

The interference-test pressure decline was analyzed using a type-curve matching method described by Earlougher. ${ }^{12}$ The type curve is shown matched to the pressure drawdown data in Fig. 22. The coordinates of the match point are:

$$
\begin{aligned}
\Delta \mathrm{p} & =1.0 \mathrm{psi} & \mathrm{p}_{\mathrm{D}} & =1.5 \\
\mathrm{t} & =10 \mathrm{hrs} & t_{D} / \mathrm{r}_{\mathrm{D}}^{2} & =2.7
\end{aligned}
$$

where $p_{D}$ and $t_{D} / r_{D}^{2}$ are dimensionless pressure and time, from the type-curve graph.

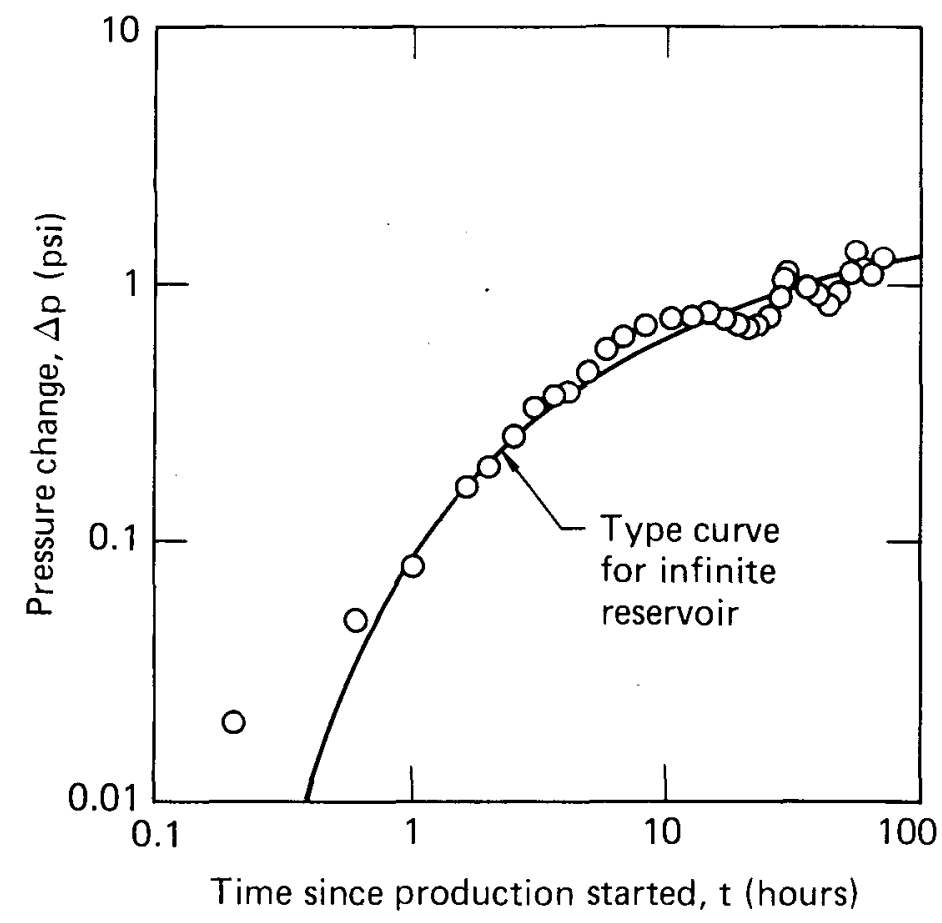

FIG. 22. Pressure drawdown in MMl resulting from $W W 1$ production at $600 \mathrm{gpm}$ from July 2 to July 5 , 1977. 
The permeability of the reservoir interval common to both MMl and WWl was calculated using

$$
\mathrm{k}=\frac{141.2 \mathrm{q \mu}}{\mathrm{h}} \frac{\mathrm{p}_{\mathrm{D}}}{\Delta \mathrm{p}}
$$

where $q$ is given in barrels per day and $p_{D}$ and $p$ are taken from the matchpoint coordinates. With $q=6857$ barrels per day $(200 \mathrm{gpm}), \mu=0.1 \mathrm{cp}$, and $h=300 \mathrm{ft}$, the permeability of the reservoir interval common to these wells is estimated to be $480 \mathrm{md}$. The reservoir storage capacity can be represented by the porosity-compressibility product

$$
\phi C_{t}=\frac{0.0002637}{r^{2}} \frac{k}{\mu} \frac{t}{t_{D} / r_{D}^{2}} \text {, }
$$

where $r$ is the distance between wells and $t$ is the match point value of time. with $\mathrm{r}=1300 \mathrm{ft}, \phi C_{t}$ is $2.8 \times 10^{-6} \mathrm{psi}^{-1}$.

There is considerable uncertainty in the permeability estimate derived from this interference test because of uncertainty in the values assigned to the flow rate $q$ and thickness of the production interval $h$. Only the top $300 \mathrm{ft}$ of the WWl production interval are in the same reservoir zone as MMl. On the basis of previous estimates of the permeability of the WWI production zone, $200 \mathrm{gpm}$ of the total $600 \mathrm{gpm}$ production from WWl was assumed to be coming from the top $300 \mathrm{ft}$ of the WWl production interval that is in common with MMl. The flow rate from WWl varied during the test by $\pm 100 \mathrm{gpm}$.

Reservoir pressure changes in MMI were monitored at the top of the production zone $(1800 \mathrm{ft})$ from June 20 to October 2, 1978. During this period, MMI was used as the production well for the GLEF. The reservoir pressure transients were sensed at the top of the production zone with the same improved pressure-transmission system as was used in the MM2 well tests. A 10-cp-viscosity silicon oil was used as the pressure transmitting medium. The pressure-transmission tubing and sensing chamber with a 30-1b sinker bar attached were lowered to approximately $1800 \mathrm{ft}$. As in the MM2 test, the tubing, attached pressure-sensing chamber, and sinker bar were encased in a 1.3-in.-diameter protective pipe with perforations near the bottom. 
The pressure record for the main portion of the MMl production test from July 7 to September 24, 1978 is shown in Fig. 23. Thermal pressure transients at the beginning of production episodes lasted only about an hour. The combination of the short periods of thermal instability with relatively long production episodes made it possible to obtain three usable drawdown tests. The results, given in Table 2, are the most reliable obtained from the MMl well testing. The pressure buildups following production episodes were very unusual

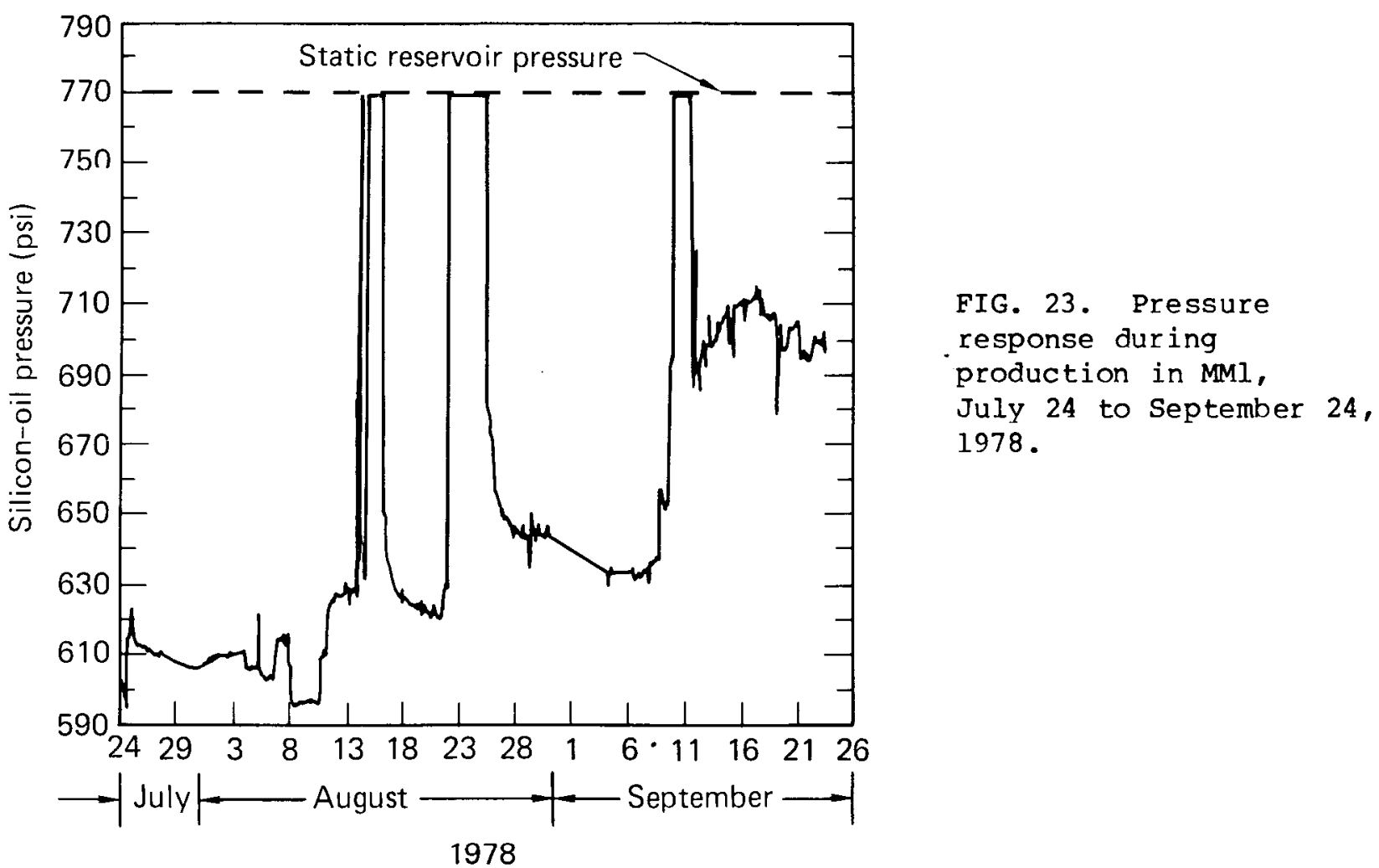

TABLE 2. Results of well tests in MM1, July 10 to September 27, 1978. (Formation thickness, $170 \mathrm{ft}$; fluid viscosity, 0.1 cp.)

\begin{tabular}{lcccc}
\hline Date & $\begin{array}{c}\text { Test } \\
\text { type }\end{array}$ & $\begin{array}{c}\text { Flow rate, } \\
\text { gpm }\end{array}$ & $\begin{array}{c}\text { Semi log } \\
\text { slope, } \\
\text { psi/cycle }\end{array}$ & $\begin{array}{c}\text { Permeability, } \\
\text { md }\end{array}$ \\
\hline $7 / 11 / 78$ & Drawdown & 600 & -10.6 & 186 \\
$7 / 24 / 78$ & Drawdown & 690 & -9.2 & 246 \\
$8 / 16 / 78$ & Drawdown & 800 & $(-22.8)$ & 224 \\
\hline
\end{tabular}


and were not analyzed. The three drawdown tests are shown in Figs. 24-26. Two values of permeability were obtained from one of the surveys (Fig. 25), a low value calculated using the slope of the line fitted to early-time data and a high value calculated from late-time data. The low permeability value is believed to be characteristic of a zone of low permeability near the well, or of an increasing production rate during the first 6 to $10 \mathrm{hr}$ or operation, or both.

A buildup test was conducted in MMl under carefully controlled conditions (Fig. 27). The well shut-in was coordinated with the ending of GLEF operations, and much early- and late-time data was obtained. For the first $10 \mathrm{~min}$ after shut-in, the pressure buildup appears quite normal. After 10 min the pressure rapidly dropped off, instead of following a trend of increasing pressure, as in the MM2 test. The most plausible explanation for this anomalous pressure decline is that a hole in the casing let relatively cool brine into the well, which quickly cooled a portion of the Hastelloy tubing, thus causing the silicon oil pressure to drop. Because this pressure drop was observed in all of the buildup data recorded during the MMI testing, the data was unusable for estimating reservoir permeability.

Despite the problems with the buildup tests, data from the MMl well tests have provided reliable estimates of permeability for the $170 \mathrm{ft}$ of permeable sands in the MMI production zone. The most representative permeability value

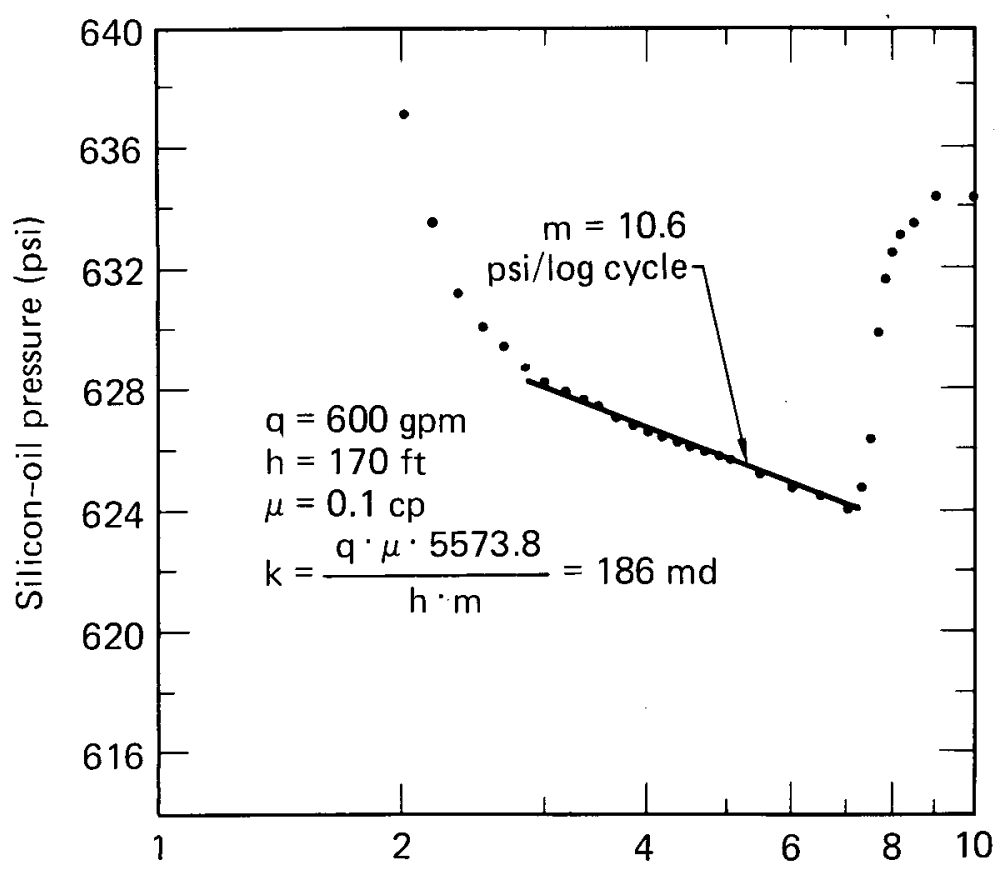

FIG. 24. Pressure drawdown in MMl starting on July 1l, 1978 .

Time since production started (hours) 


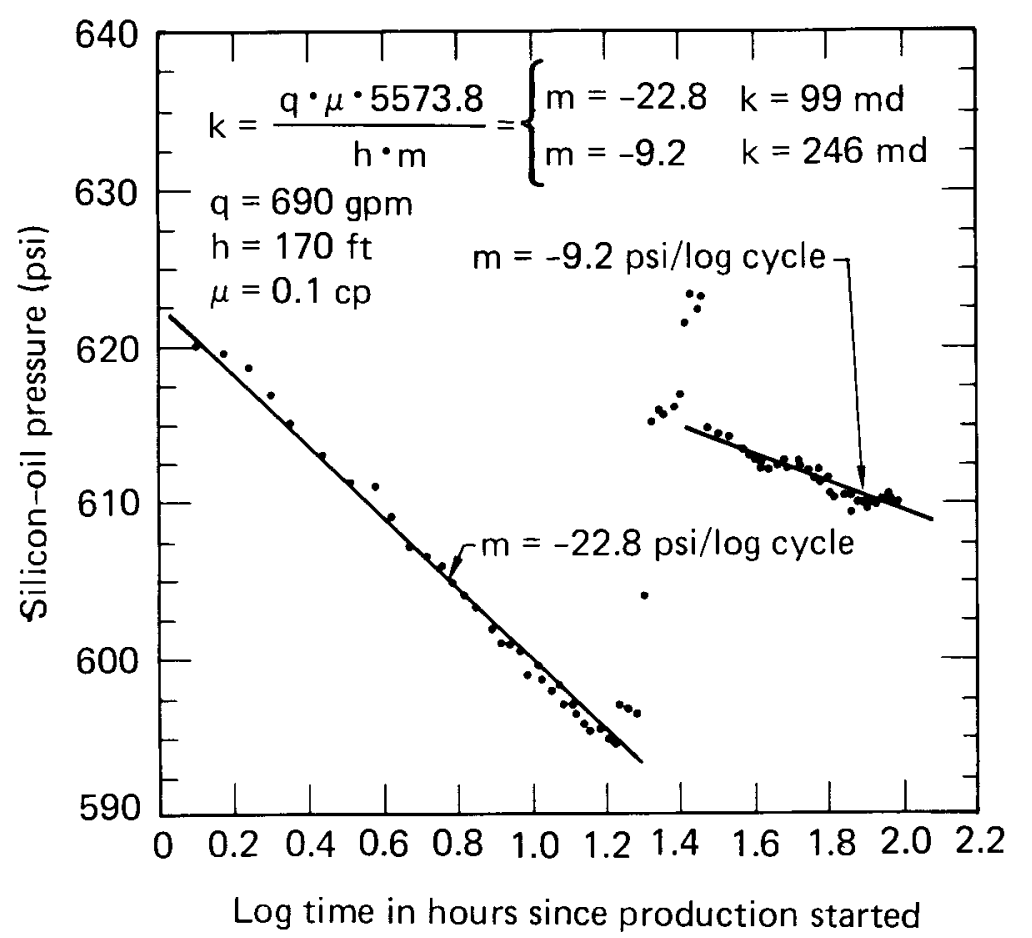

FIG. 25. Pressure drawdown in MMI starting on July 24, 1978 .

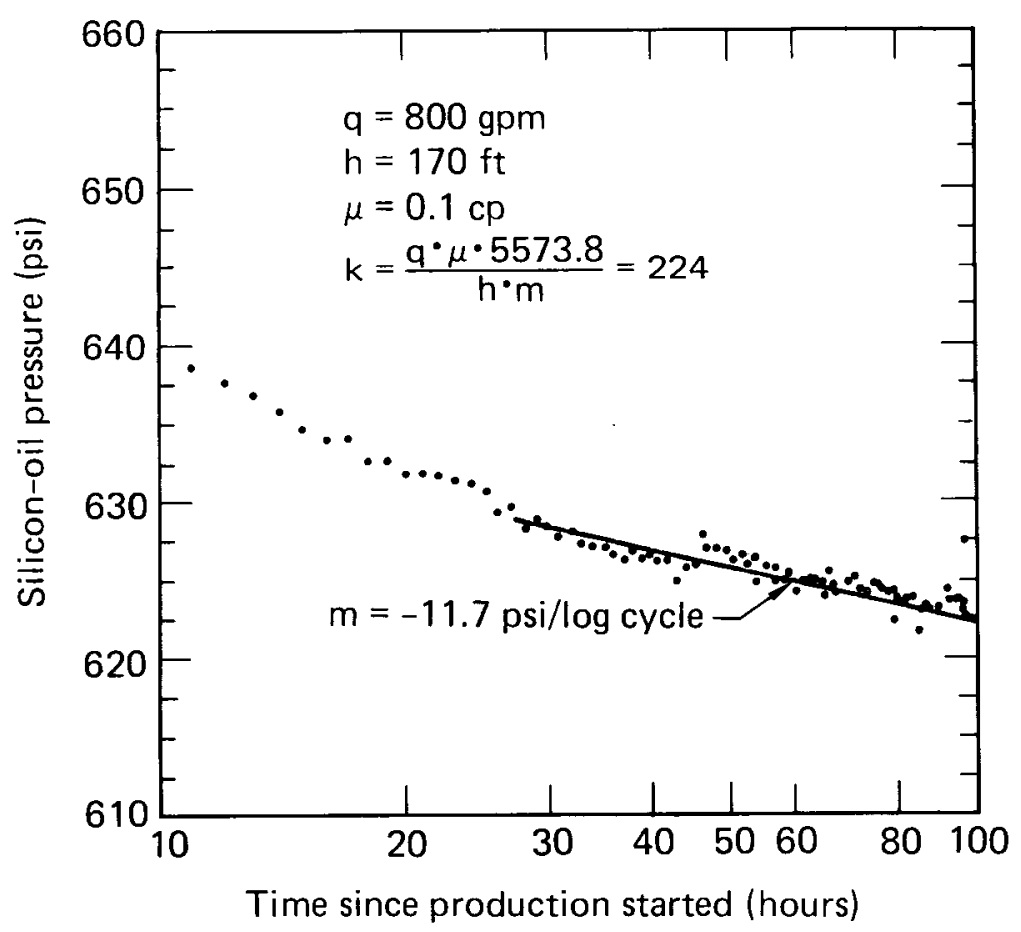

FIG. 26. Pressure drawdown in MMl starting on August 16, 1978 . 


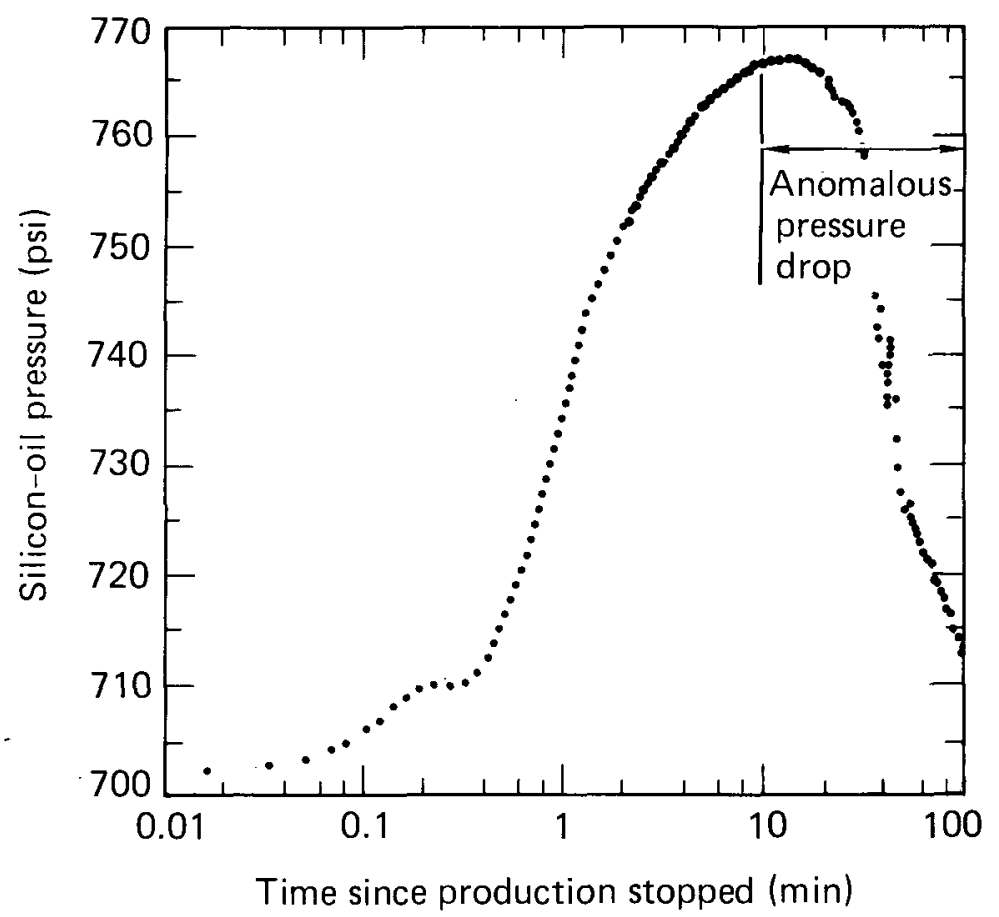

FIG. 27. Pressure huildup in MMI starting on September $24,1978$.

for the permeable sands in the MMl production zone is taken to be 220 ma. This value is in reasonably good agreement with values obtained from drillstem tests conducted on MMI and WWI. Results of the drillstem tests are shown in Table 3 .

RESULTS FROM OBSERVATION WELLS

At various times during the well-testing program, MM4, SN3, and EL3 were equipped as observation wells. The location of these wells is shown in Fig. 1. Pressure transients were recorded at shallow depths (150 to $450 \mathrm{ft}$ ) in all of these wells. The main purpose of monitoring the wells was to observe the interference effects from the production and injection wells. A secondary purpose was to record other reservoir transients such as those brought on by earth tides.

MM4 was instrumented to observe vertical interference effects caused by injection into MM3. MM3 and MM4 are only 50 ft apart, and the top of the injection interval in MM3 is $80 \mathrm{ft}$ below the bottom of MM4. In this $80-\mathrm{ft}$ vertical zone is a 40-ft-thick, horizontal, continuous layer of shale which runs through all of the wells in vicinity of the GLEF. Pressure changes in M4 were observed using a Sperry Sun pressure-transmission system from July 12 to August 10, 1977, and an HP pressure-and-temperature-logging tool from August 10 to September 30, 1977. The Sperry Sun pressure-sensing chamber was 
TABLE 3. Drillstem test (DST) analysis using both the curve-matching technique $^{13}$ and a multirate analysis. ${ }^{2}$

\begin{tabular}{lcccc}
\hline \multirow{2}{*}{ Well } & $\begin{array}{c}\text { Depth } \\
\text { No. }\end{array}$ & interval (ft) & Curve matching & Multirate analysis \\
\hline MM1 & 2 & $1854-1862$ & -- & - \\
& 3 & $1862-1870$ & 175 & 160 \\
& 1 & $2556-2564$ & 121 & -1 \\
WWl & & & 113 & 247 \\
& 1 & $1227-1233$ & 81 & 177 \\
& 2 & $1907-1913$ & 82 & \\
\hline
\end{tabular}

suspended at 22-ft depth in the well and the HP quartz pressure gauge was suspended at $450-\mathrm{ft}$ depth.

The Sperry Sun equipment was replaced with HP equipment because of a 3.0 psi diurnal pressure variation sensed by the Sperry sun pressuretransmission-and-measurement system, which was partly caused by the effects of diurnal temperature variations on the gas-filled pressure transmission system. Diurnal pressure noise was reduced to a variation of about 1.5 psi by use of the HP equipment.

MM3 was used for injection of spent brine on a continuous basis from July 12 to August 22, 1977 and again from September 13 to September 30, 1977 . The pressure response in MM4 is shown in Fig. 28, where the observed signal noise is evident. The pressure data was filtered using a moving-average technique. From the resulting smoothed data (Fig. 29), the vertical permeability across the shale layer separating the two wells was estimated to be between 0.1 and $1.0 \mathrm{md}$, using the ratio method. ${ }^{14}$ It is possible that an incomplete cement bond around the MM3 casing allowed communication between MM3 and MM4. The pressure response in MM4 to injection into MM3 decreased as time went by. By January 1978, no response could be detected in MM4 during injection into MM3. The vertical flow paths through either the shale layer or around the MM3 casing were plugged with suspended solids and precipitated silica.

SN3 and EL3 were instrumented to record interference effects and monitor reservoir pressure transients brought on by earth tides. Paroscientific 


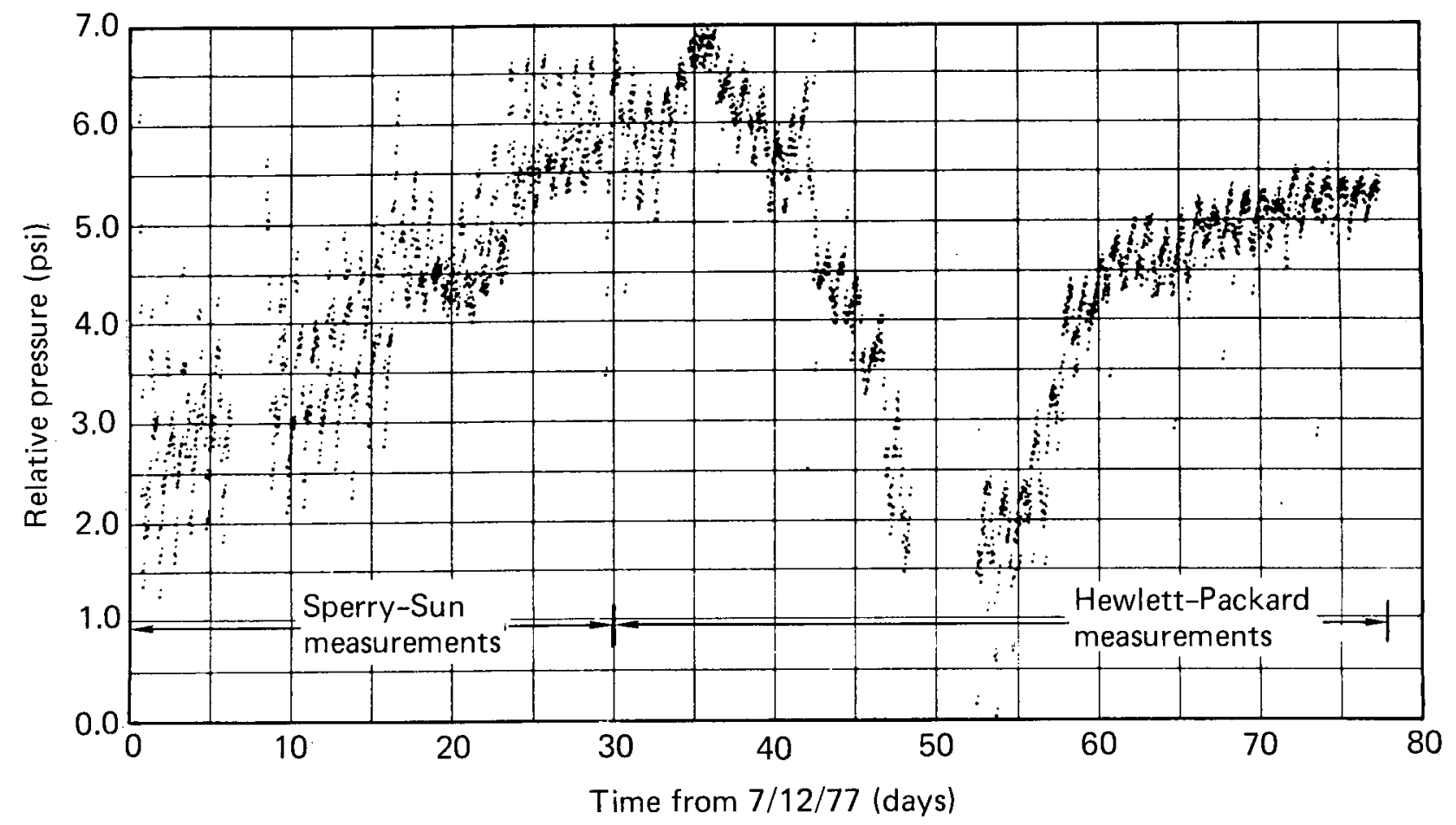

FIG. 28. Pressure fluctuations in the observation well MM4, July 12 to September 27, 1977. (Data obtained using Sperry Sun and Hewlett-Packard equipment.)

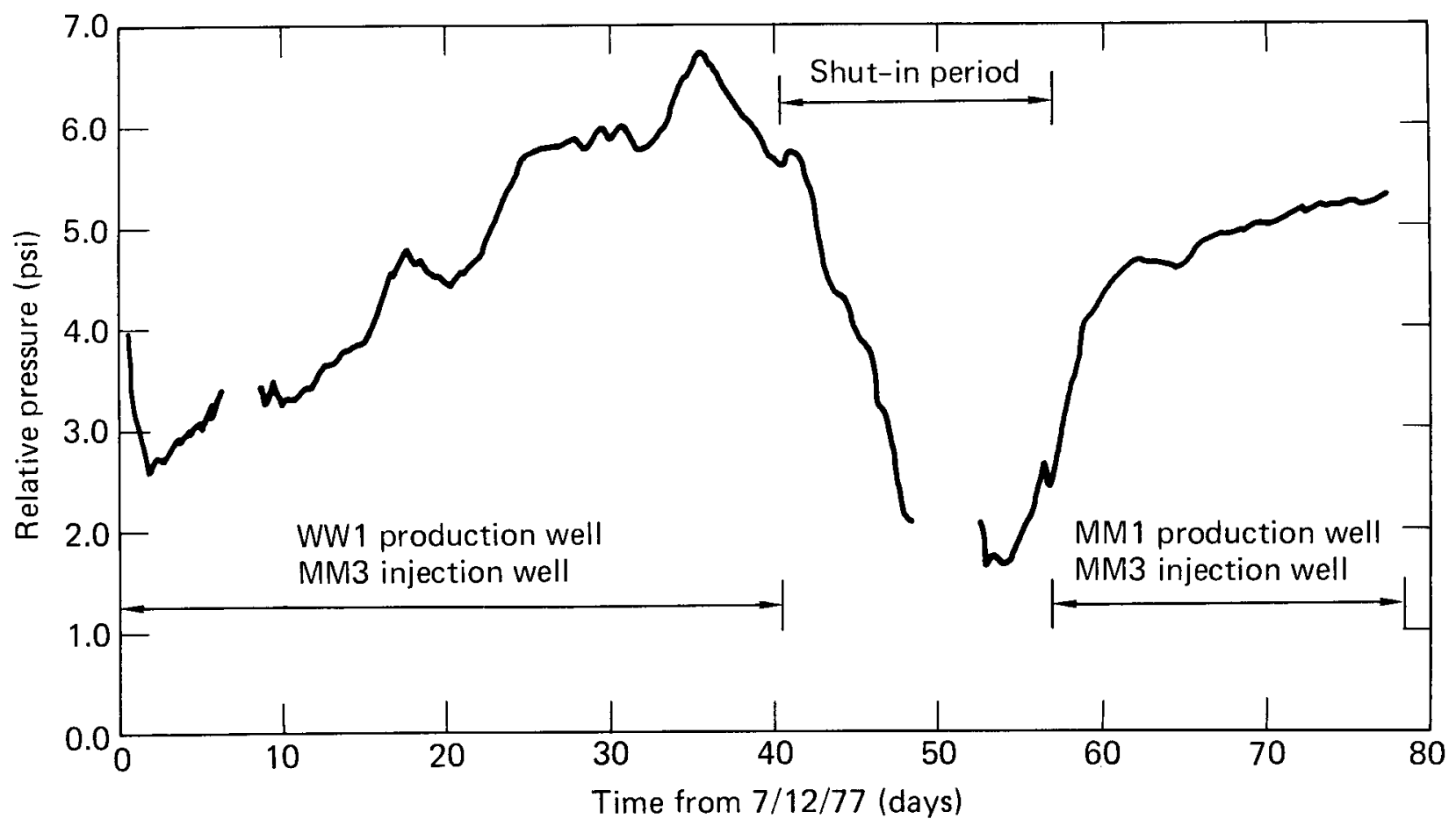

FIG. 29. Smoothed pressure-fluctuation data from MM4, July 12 to September 27, 1977. The data from Fig. 28 were smoothed using a 24-hr moving average around each data point. 
submersible quartz pressure gauges, suspended at a depth of about $150 \mathrm{ft}$, were used in both wells. Both wells produced an excellent five-month reservoir pressure-variation record. Both diurnal and semidiurnal variation in response to earth tides was identified. Response to production or injection at the GLEF well-field was very small and of limited duration because of the GLEF well-field operating schedule and the substantial distance that separates SN3 and EL3 from the production and injection wells.

\section{CONCLUSIONS}

Conducting well tests in a geothermal field, where temperatures at reservoir depth range from 390 to $570^{\circ} \mathrm{F}$ and wells produce hypersaline brine, is a challenging task. Measurement of pressure transients in the geothermal wells required modification of existing instrumentation and fabrication of new pressure-sensing devices. Commercially available quartz pressure transducers can be used at shallow depths in observation wells and at reservoir depth in injection wells cooled by injection of spent brine. The electrical connections in the cablehead assembly of these devices, between the electromechanical cable and the transducer package, can be successfully isolated from the corrosive brine by filling the assembly with chlorofluorocarbon grease. Small-diameter, corrosion-resistant, Hastelloy C-276 tubing filled with silicon oil effectively transmitted pressure signals to the wellhead from reservoir depth in production wells. The oil is a more appropriate pressure transmission medium than nitrogen or helium gas because spurious pressure transients in the oil-filled tubing, caused by temperature transients in the wellbore and by diurnal temperature variation at and near the surface, are smaller and are effectively filtered. Commercially available line-wiper and lubricator equipment provided a serviceable wellhead seal around electromechanical transducer cable and pressure-transmission tubing.

Analysis of a pressure dropoff test in MM3 provides a range of estimates of the permeability of a 200-ft-thick reservoir interval of from 250 to $1000 \mathrm{md}$. The characteristics of the pressure dropoff in MM3 imply that flow occurs through both the reservoir matrix and through fractures that transect the matrix. The injection efficiency of MM3 is thought to have declined as a result of plugging of the casing slots and surrounding reservoir by precipitation of siliceous scale and deposition of suspended solids from the injected 
brine. Idle periods in injection-well lifetimes are generally followed by marked impairment of injection efficiency. The injection history of MM3 indicates that its lifetime without preinjection brine treatment would be about 1.50 days at an injection-flow rate of $600 \mathrm{gpm}$. Cycling the brine through settling tanks, with a residence time in the tanks of two or three hours, would increase well lifetime to about two years, at the same injectionflow rate. Other workers have shown that brine treatment with a reaction clarifier in conjunction with pressure filtration could further extend injection-well life.

Buildup and drawdown tests of MM2 yield an estimated permeability of 70 md for the 177-ft-thick effective reservoir-production interval penetrated by the well. Three drawdown tests provide an average estimated permeability of $220 \mathrm{md}$ for the 170-ft-thick production interval in MMl. The permeability of the geothermal reservoir is probably between 70 and 250 md. Greater permeability, up to $1000 \mathrm{md}$, may occur. It may not be coincidental that the lowest value of permeability, that derived from testing MM2, is related to the deepest production zone of any well tested. Production from MM2 improved its injection efficiency.

An interference test of the series between WW1 and MMI provided an estimate of the reservoir porosity-compressibility product of $2.8 \times 10^{-6} \mathrm{psi}^{-1}$. The permeability value derived from this test may be substantially in error because of uncertainty concerning the brine flow rate from WWl derived from the reservoir interval common to both wells. The estimated porosity-compressibility product suffers from the same shortcoming, but is the only value of the storage parameter obtainable from the test series.

The pressure responses of the various transient well tests seem to be characteristic of a confined, nonleaky reservoir. The vertical permeability of a 40-ft-thick shale layer within the reservoir is estimated to be between 0.1 and $1 \mathrm{md}$, based on a ratio test between MM3 and MM4. None of the tests provides evidence of local positive or negative lateral hydraulic boundaries within the reservoir.

\section{ACKNOWLEDGEMENTS}

The contributions that others have made to this study are gratefully acknowledged. L. B. Owen lent technical assistance and encouragement in all 
phases of the work. S. Zajac and L. Brassfield, of Magma Power Company, provided invaluable field support during the instrumentation and conduct of the well tests. J. Nugent and D. Malliner of New Albion Resources Company gave their assistance in coordinating the well tests with the operating plans of SDG\&E. Rosalie Robinette aided in reduction and compilation of the GLEF operating records. Alfred Goldberg specified use of Hastelloy C-276 for the pressure transmission tubing. He subsequently located a fabricator for the tubing and was instrumental in defining welding requirements for the joining of several tubing lengths. The HP pressure monitoring equipment was made available for use in the well testing program by L. B. Ballou. The chlorofluorocarbon grease used to protect cable head assemblies was recommended by L. E. Lorensen. 


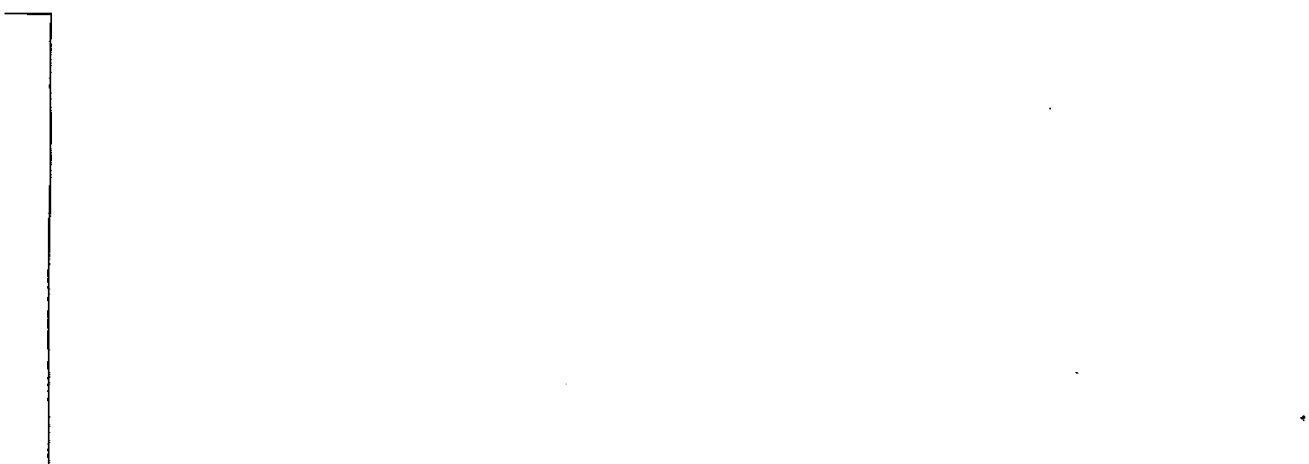

. 
APPENDIX A--WELL FIELD OPERATIONAL HISTORY

A history of the Magmamax and Woosley wells and the GLEF is presented to provide a framework within which to view the well tests and their results. The statistics given cover a period from 1972, when the wells were drilled, to September 24,1978 , when the MMl production test was completed.

Table A-1 gives construction, production, and injection statistics for the Magmamax and Woolsey wells. Total fluid production from these wells, in terms of equivalent brine volume, was $329.4 \times 10^{6}$ gal as of September 24 , 1978. The total volume of spent brine reinjected into the geothermal reservoir $\left(260.6 \times 10^{6}\right.$ gal) was approximately 208 less than the amount produced because some of the water condensed from the steam was used at the surface. Essentially all the operating sequences for the wells supporting the

TABLE A-1. Construction, production, and injection history for Magmamax and Woosley wells.

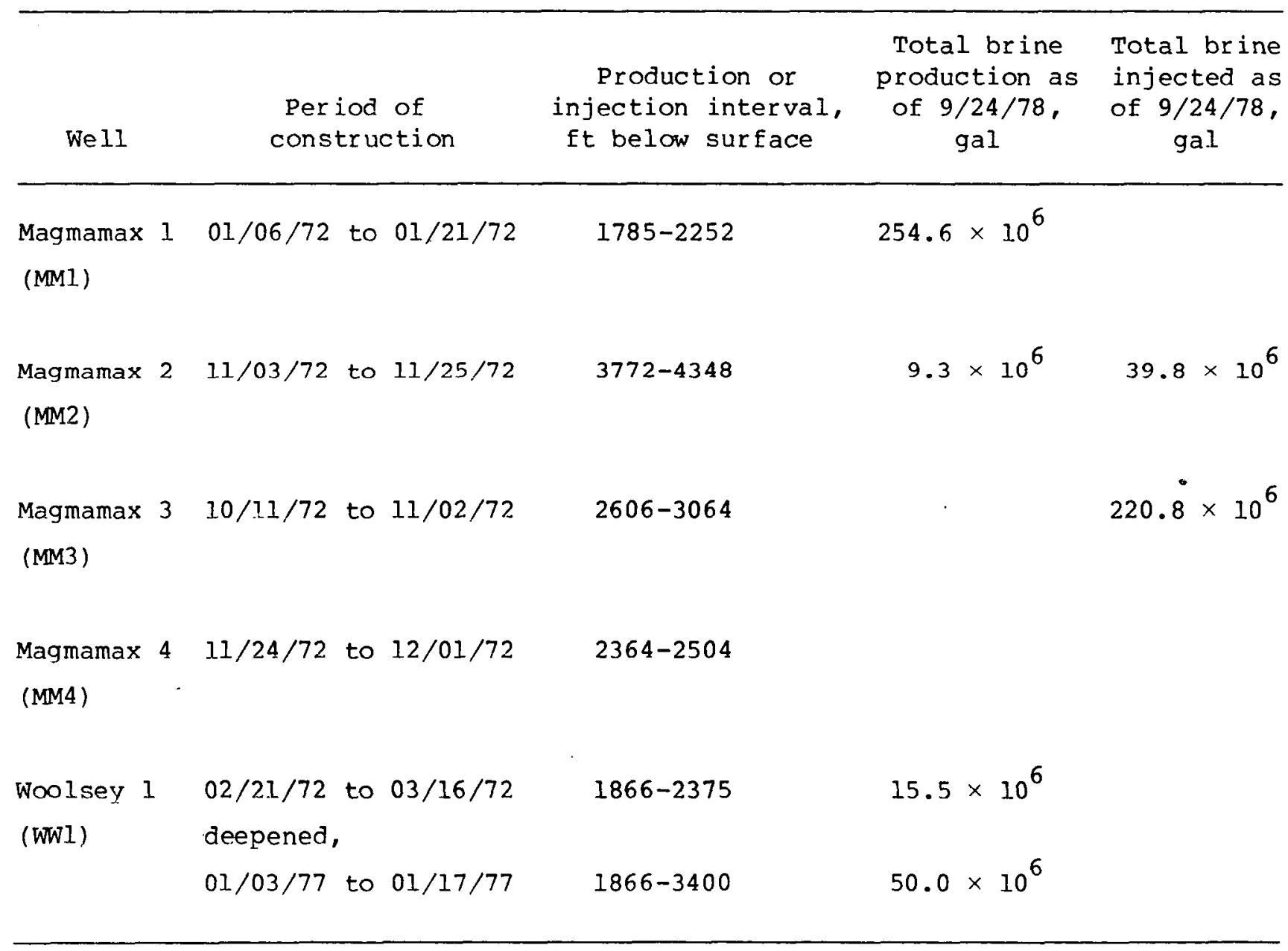


GLEF involved production of geothermal fluids from one well and injection of the spent brine into another. There were brief periods of injection into two wells (MM3 and MM2) amounting to only a few hours. Some periods of production from two wells (MMI and WWl) also took place, but amounted to a total of only a few days.

The total brine flow through the GLEF as of September 24, 1978 was $311.0 \times 10^{6} \mathrm{gal}$. The GLEF began operation in May 1976. The average brine flow rate through the facility during its periods of operation was $443 \mathrm{gpm}$. The operational history of wells in the vicinity of the GLEF is summarized in Fig. A-I, which depicts periods of injection of brine into wells, of production of brine from wells, and of operation of the GLEF. The use of wells MM4, SN3, and EL3 for observation of'reservoir pressure changes caused by production from and injection into other wells is also shown. The first production-injection operation occurred in 1973, but most of the production and reinjection of geothermal brine has occurred since operation of the GLEF commenced in 1976. MMl was the major source of brine with a total volume of production four times that of WWI. Both wells were originally designed to supply brine to the GLEF. MMI was used more because of its greater brine temperatures, pressures, and flow rates.

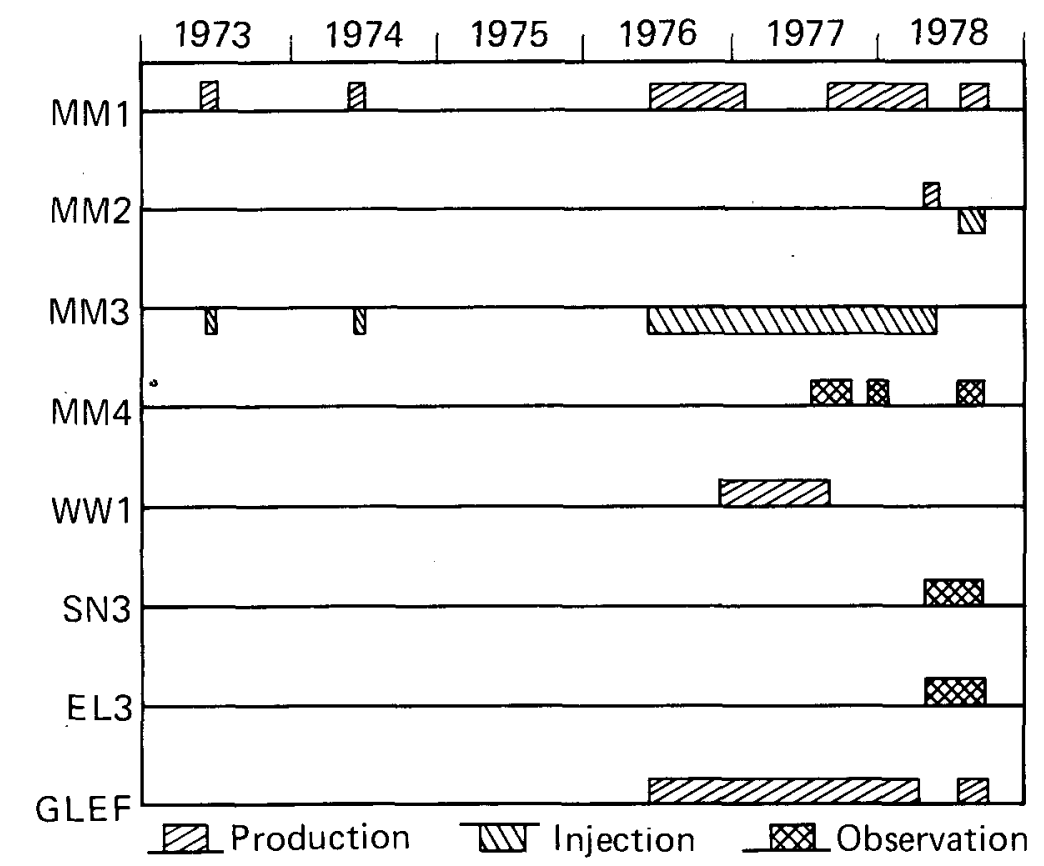

FIG. A-1. Operational history of geothermal wells and the GLEF at the Salton Sea Geothermal Field, 1973-].978. 
APPENDIX B--MAGMAMAX NO. 3 INJECTION HISTORY

Magmamax No. 3 (MM3) was the primary disposal well for the injection of spent brine produced from MM1, MM2, and WW1 in the course of SSGF and GLEF operations from 1972 until July 1978. In July 1978, the wellhead injection pressures necessary to force the flow of brine into MM3 exceeded the available pumping capacity and the well was abandoned.

A total volume of about $220.8 \times 10^{6}$ gal of spent brine was injected into MM3 at an average rate of $443 \mathrm{gpm}$. Most of this volume had been cycled through the GLEF and was produced from MMI and WWI. Of the 40 periods of injection into into MM3, five were longer than $700 \mathrm{hr}$ and one was more than $1000 \mathrm{hr}$. Wellhead injection pressures ranged from 0 to 500 psi.

The injection history of MM3 began in 1973 with brine produced from MMl. This production-injection cycle was short and only $1.6 \times 10^{6} \mathrm{gal}$ of spent brine was injected. A similar short production-injection cycle in 1974 resulted in injection of $1.8 \times 10^{6}$ gal of brine. Detailed wellhead pressure data were not recorded during these periods. Observations by those involved with these early production-injection cycles indicate that MM3 accepted the spent brine by gravity flow. ${ }^{B-1}$ No wellhead overpressure was required to drive the injection. High scaling rates were observed in the surface equipment and a high suspended-solids load was observed in the brine during the 1973 and 1974 cycles. MM3 was idle after the 1974 cycle until the start of GLEF operations in May 1976.

A wellhead pressure of about $100 \mathrm{psi}$ was initially required to inject spent brine into MM3 in the GLEF program. The increased wellhead injection pressure over that of the 1973 and 1974 cycles indicates that significant impairment of MM3 had occurred. It is presumed that the slotted well casing in the injection interval and the surrounding reservoir were partially plugged by deposition of siliceous scale: When the well was shut in after injection cycles, suspended solids in the brine settled out and partially plugged available flow paths in the wellbore, through casing perforations, and in the reservoir rock. The volume of spent brine injected into MM3 each day during the period from May 3, 1976 to April 13, 1978 is shown in Fig. B-1.

Analyzing the wellhead injection pressure performance of MM3 is difficult because of the many short flow periods and the variable average daily injected flow rates; for each daily average wellhead injection pressure there is a corresponding daily average flow rate. To facilitate data analysis, all of 


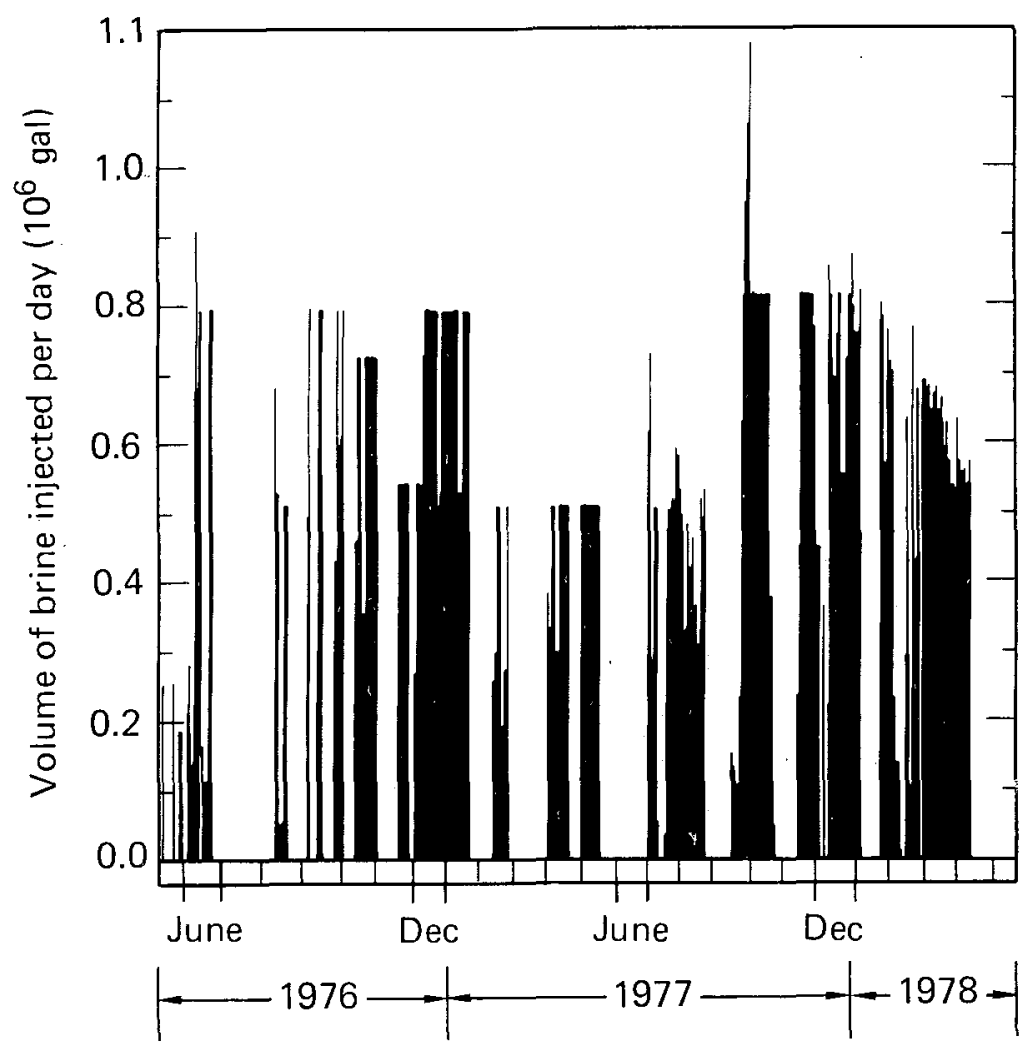

FIG. B-1. Volume of spent brine injected into MM3, May 3, 1976 to April 13, 1978. The total volume injected was $210.0 \times 10^{6} \mathrm{gal}$.

the injection pressures were adjusted to a common flow rate of $443 \mathrm{gpm}$, the overall injection rate into MM3, using the following equation:

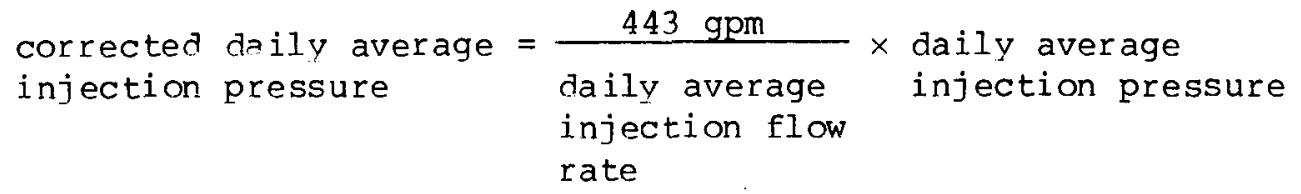

Figure B-2 shows the corrected daily average injection pressure as a function of cumulative volume of brine injected into MM3 during the period from May 3, 1976 to April 13, 1978. (The spent brine initially was untreated prior to injection.) As seen in Fig. B-2, the average injection pressure increased at a rate of 1.7 psi per million gallons of brine injected from May 3, 1976 to February 15, 1977. On February 15, 1977, following a major descaling of the GLEF and the injection line, a large amount of solid material was accidently injected into MM3, which resulted in a temporary failure of the well. In March, April, and May of 1977, several remedial workovers were conducted on MM3. These included a casing scraping and bailing job, a wellbore acid treatment, and a hydraulic fracture treatment. Although the well was recovered for further use, injection pressures were not returned to the levels that had pertained before the injection accident. 


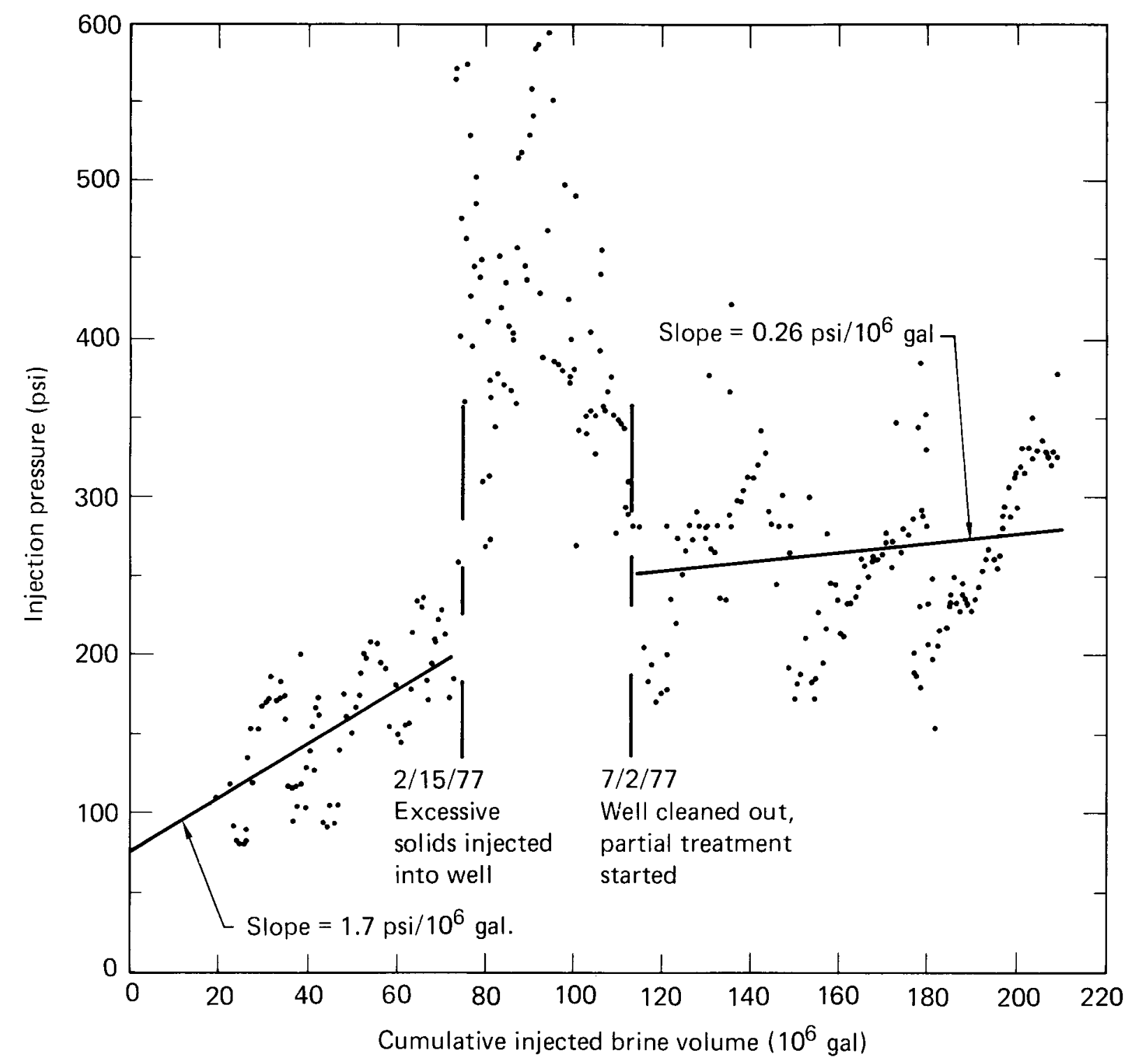

FIG. B-2. MM3 wellhead injection pressure as a function of the cumulative volume of brine injected, May 3, 1976 to April 13, 1978. The injection pressures are the average pressures for each day corrected to a flow rate of $443 \mathrm{gpm}$.

In July, August, and September of 1977, settling tanks were installed to remove some of the suspended solids from the spent brine before it was injected into MM3. Brine residence time in the tanks was short (about 2 to $3 \mathrm{hr}$ ), but the treatment effectively removed some of the material responsible for clogging MM3. This simple preinjection brine treatment reduced the rate of increase in average injection pressure from 1.7 to 0.26 psi per million gallons of brine injected. 
Injection pressures shown in Fig. B-2 vary considerably about the straight-line segments that map their large-scale trends. This apparent pressure noise is actually composed of patterns of pressure change associated with the individual continuous injection periods. Some of these patterns can be discerned in the graph of MM3 injection pressure for the period from August 5, 1977 to April 13, 1978 (Fig. B-3). There were four periods of injection in this time interval, each of which is marked by initially high injection pressures that fall to a minimum and then climb until injection ceases.

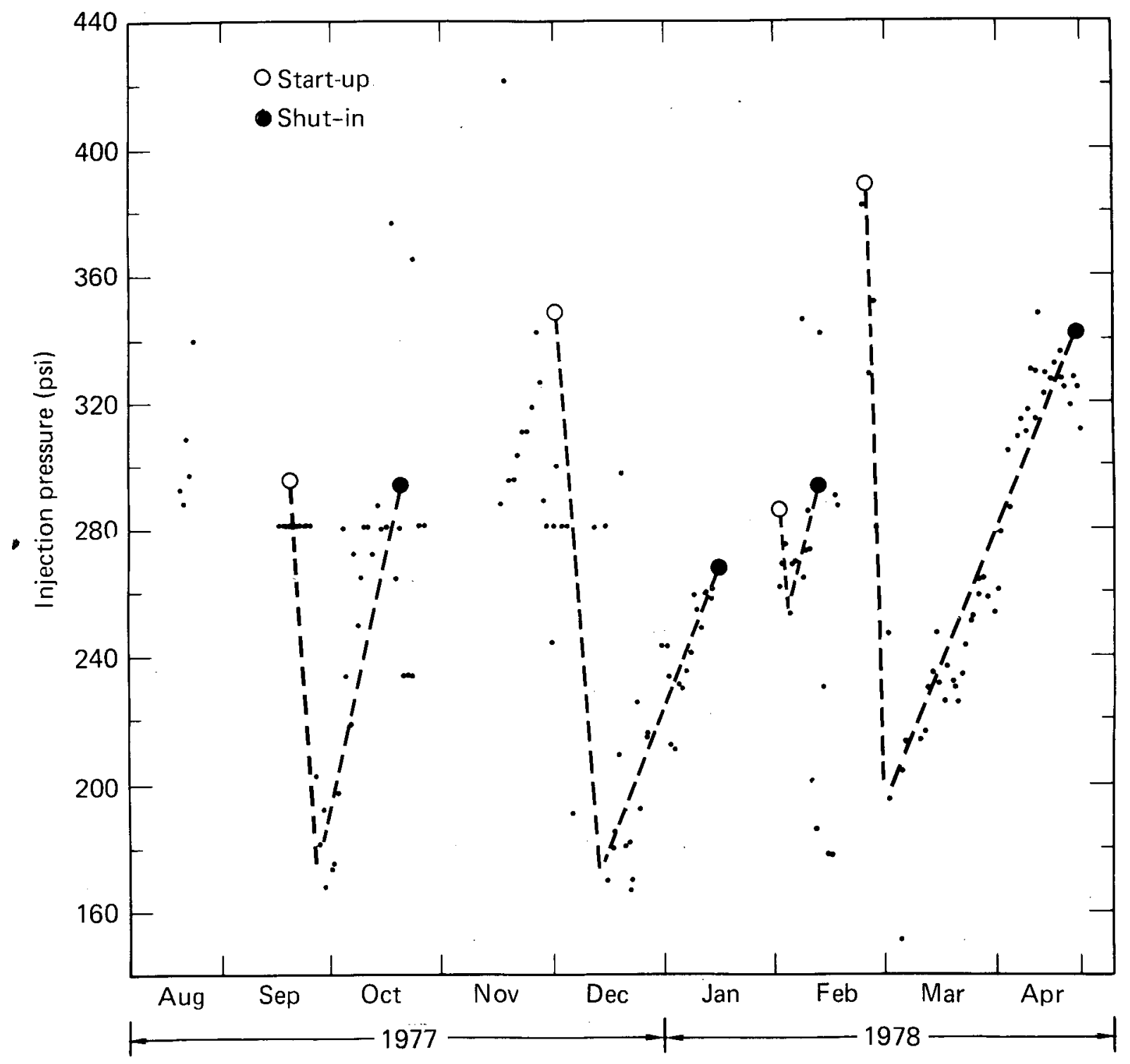

FIG. B-3. MM3 wellhead injection pressure during brine injection from August 5, 1977 to April 13, 1978. The injection pressures are the average pressures for each day corrected to a flow rate of $443 \mathrm{gpm}$. 
The last of these injection periods, from February 17, 1978 to Apri1 13, 1978, continued for more than $1000 \mathrm{hr}$ and is documented with the best injection-pressure measurements of the MM3 injection history. The injectionpressure history of this period (shown in Fig. B-4) illustrates the typical injection pressure pattern for MM3. When injection was first started in this episode, a total wellhead pressure of 400 to 500 psi was required to "breakover" the well and initiate brine injection flow. In seven days the injection pressure decreased by about $200 \mathrm{psi}$. The cause of this pressure decline may have been that the initially higher-pressured flow reopened partially plugged flow pathways in the subsurface injection interval. As injection continued, the required injection pressure increased in a systematic manner to an apparent maximum value within 50 days. From this point the injection pressure seemed to decline until the end of the injection period. The increasing pressure was probably the result of pressure build-up in the geothermal reservoir and increasing flow resistance in the wellbore, across the slots in the casing, and across some nearby zone of reduced reservoir permeability in the injection interval. If this explanation is accurate, the apparent decrease in injection pressure after 50 days is difficult to explain. Perhaps the pressure increased sufficiently to reopen a partially plugged flow pathway in or near the wellbore. Following the completion of the production-injection period of February 17 to April 13, 1978, which had involved production from MMl, a period of

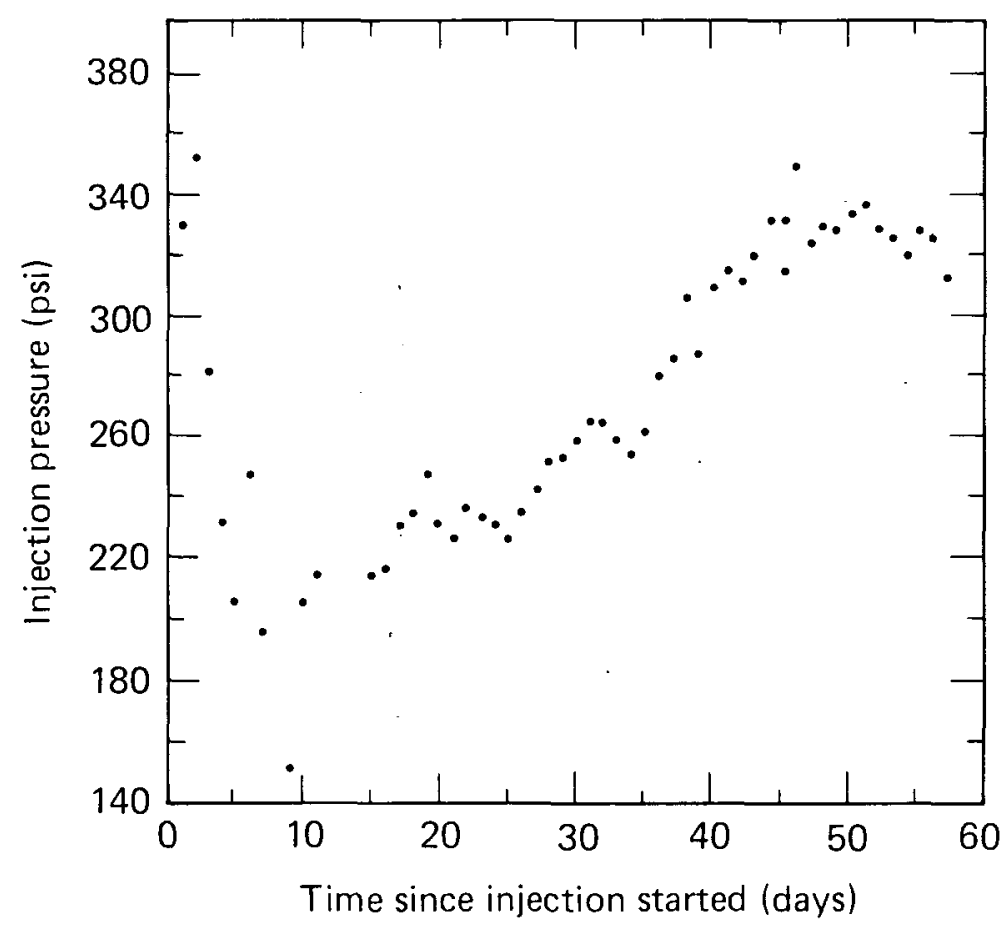

FIG. B-4. MM3 wellhead injection pressure during brine injection from February 17 to April 13, 1978. The injection pressures are the average pressures for each day corrected to a flow rate of $443 \cdot \mathrm{gpm}$. 
production-injection was carried out from April 24 to May 15, 1978 with production from MM2 and injection into MM3. This was the final significant injection period for MM3, and lasted $331 \mathrm{hr}$. The average rate of injection into MM3 was $400 \mathrm{gpm}$ at injection pressures of 350 to $450 \mathrm{psi}$. Injectionpressure data obtained during this period are incomplete and highly variable because of instrumentation and injection pump problems.

Further injection of spent brine from MMI into MM3 was attempted after the April 24 to May 15, 1978 injection episode. High injection pressures when production-injection was attempted on July 10, 1978 caused MM3 to be abandoned. MM2 then became the primary injection well for the GLEF well field.

Injection-well lifetime at the GLEF well field was defined as the operating time until the wellhead injection pressure exceeded the pumping capability of 500 psi. The MM3 history indicates that with no pretreatment of the brine, well lifetime would be about 150 days at an injection rate of 600 gpm. By circulating the spent brine through settling tanks prior to injection, well lifetime can be extended to about two years. It has been shown that passing the spent brine through a reaction clarifier and pressure filters can substantially improve its injectability. ${ }^{\mathrm{B}-2}$ Using this treatment process, dissolved silica in the brine is reduced to below saturation and the suspended solids load in the brine is reduced to less than $5 \mathrm{ppm}$ (less than $1 \mu \mathrm{m}$ in diameter). ${ }^{\text {B-3 }}$ with this type of preinjection brine treatment, salton sea injection-well lifetimes could be increased substantially beyond two years. ${ }^{B-4}$ 
1. T. D. Palmer, J. H. Howard, and D. P. Lande, Geothermal Development of the Salton Trough, California and Mexico, Lawrence Livermore Laboratory, Li.vermore, CA, UCRL-51775 (1975).

2. R. C. Schroeder, Reservoir Engineering Report for the Magma-SDG\&E Geothermal Experimental site near the Salton Sea, California, Lawrence Livermore Laboratory, Livermore, CA, UCRL-52094 (1976).

3. J. D. Tewhey, Geologic Characteristics of a Portion of the Salton Sea Geothermal Field, Lawrence Livermore Laboratory, Livermore, CA, UCRL-51167 (1977) .

4. L. J. P. Muffler and B. R. Doe, "Composition and Mean Age of Detritus of the Colorado River Delta in the Salton Trough, Southeastern California," Jour. Sed. Petrology $38,384-399$ (1968).

5. G. P. Zehal, George Zebal and Associates, Newport Beach, CA, private communication (August 1978).

6. M. A. Chan and J. D. Tewhey, Subsurface structure of the Southern Portion of the Salton Sea Geothermal Field, Lawrence Livermore Laboratory, Livermore, CA, UCRL-52354 (1977) .

7. D. Towse and T. D. Palmer, Summary of Geology at the ERDA MAGMA-SDG\&E Geothermal Test Site, Lawrence Livermore Laboratory, Livermore, CA, UCID-1.7008 (1976).

8. P. W. Kasameyer and L. W. Younker, "Temperature Gradient Analysis" in the LLL Geothermal Energy Status Report January 1976 - January 1977 , Lawrence Livermore Laboratory, Livermore, CA, UCRL-50046-76 (1977).

9. L. J. P. Muffler and D. E. White, "Active Metamorphism of Upper Cenozoic Sediments in the Salton Sea Geothermal Field and the Salton Trough, South-Eastern California," Geol. Soc. America Bul1. 80, 157-182 (1969).

10. T. B. Coplen and P. Kolesar, Investigations of the Dunes Geothermal Anomaly, Imperial Valley, California: Part 1. Geochemistry of Geothermal Fluids, University of California, Riverside, CA, IGPP-UCR-74-18 (1974).

11. T. D. Streltsova, "Hydrodynamics of Groundwater Flow in a Fractured Formation," Water Resources Research 12, 405-414 (1976).

12. R. C. Earlougher, Jr., Advances in well Test Analysis, Society of Petroleum Engineers, Monograph V. 5 (1977). 
13. H. J. Ramey, R. G. Agarwal, and I. Martin, "Analysis of 'Slug Test' or DST Flow Period Data," J. Cdn. Pet. Tech. (July-September 1975), p. 37.

14. S. P. Neuman and P. A. Witherspoon, "Field Determination of the Hydraulic Properties of Leaky Multiple Ãquifer Systems," Water Resources Research $\underline{8}$, 1284-1298 (1972).

B-l. D. K. Mulliner, San Diego Gas and Electric Company, private communication (1978):

B-2. J. D. Tewhey, M. A. Chan, P. W. Kasameyer, and L. B. Owen, Development of Injection Criteria for Geothermal Resources, Geothermal Resources Council Transactions, Vol. 2 (1978), pp. 649-652.

B-3. R. Quong, N. D. Shoepflin, G. E. Tardiff, and F. R. McLain, "Processing of Geothermal Brine Effluents for Injection," Geothermal Resources Council Transactions $\underline{2}$, 551-554 (1978).

B-4. L. B. Owen, P. W. Kasameyer, R. Netherton, and L. D. Thorson, "Predicting the Rate by Which Suspended Solids Plug Geothermal Injection Wells," in Proc. Third Annual Workshop on Geothermal Reservoir Engineering, Stanford University, December 1977, Stanford University, Stanford, CA, SGP-TR-25 (1978), p. 163. 